\title{
FLIGHT MOTOR PATTERNS OF LOCUSTS RESPONDING TO THERMAL STIMULI
}

\author{
by \\ KELLY LOUISE SHOEMAKER
}

A thesis submitted to the Department of Biology

in conformity with the requirements for the degree of Master of Science

\author{
Queen's University \\ Kingston, Ontario, Canada
}

August, 1997

copyright 0 Kelly Louise Shoemaker, 1997 
National Library of Canada

Acquisitions and Bibliographic Services

395 Wellington Street Ottawa ON K1A ON4 Canada
Bibliothèque nationale

du Canada

Acquisitions et

services bibliographiques

395. rue Wellington

Ottawa ON K1A ON4

Canada
Your file Vocre reforence

Our the Notre retarence
The author has granted a nonexclusive licence allowing the National Library of Canada to reproduce, loan, distribute or sell copies of this thesis in microform, paper or electronic formats.
L'auteur a accordé une licence non exclusive permettant à la Bibliothèque nationale du Canada de reproduire, prêter, distribuer ou vendre des copies de cette thèse sous la forme de microfiche/film, de reproduction sur papier ou sur format électronique.

L'auteur conserve la propriété du droit d'auteur qui protège cette thèse. $\mathrm{Ni}$ la thèse ni des extraits substantiels de celle-ci ne doivent être imprimés ou autrement reproduits sans son autorisation. 


\begin{abstract}
Although correctional and intentional steering manoeuvres are superficially similar, they differ in several important respects. The most profound difference between the two is the production of large forewing asymmetries in angle of elevation during the downstroke that are not obvious in correctional steering. We investigated the flight motor patterns during steering responses to a radiant heat source. We found asymmetries in forewing first basalar ( $\mathrm{m} 97$ ) activity on left and right sides that were strongly and positively correlated with forewing asymmetries. Additionally, an earlier firing of $\mathrm{m} 97$ was associated with an increased number of spikes per muscle burst. Muscle asymmetry in the second basalar muscles (m98) and pleuroalar muscles (m85) were not significantly different from the changes observed in m97. The hindwing first basalar (m127) shifted its asymmetry in the opposite direction. The forewing subalar muscle (m99) did not shift its asymmetry with the same magnitude as $\mathrm{m} 97$. Instead, it was phase-shifted relative to $\mathrm{m} 97$ on left and right sides, suggesting its role as a supinator. We conclude that large asymmetries in the elevation angle of the forewings during the downstroke, such as are evident in intentional steering, are generated by bulk shifts in the activation times of forewing depressor muscles to cause a relative shift in the time of stroke reversals of the two forewings.
\end{abstract}




\section{ACKNOWLEDGEMENTS}

First and foremost, I would like to thank my supervisor, Dr. R. Meldrum Robertson, for his encouragement and support over the past few years, and for the countless hours given to help me prepare my thesis.

I would also like to thank my committee members, Dr. Laurene Ratcliffe and Dr. Doug Munoz for their advice and assistance in developing this project.

Warm thanks go to the other members of the lab, especially Christine Gee, Jeff Dawson, and Jack Gray for giving moral support and advice when I needed it. We shared many good times over a pint of beer, a plate of chicken fingers, or a midnight chocolate bar.

Finally, I extend many thanks to Mom, Dad, and especially Pat for helping me maintain my sanity while I was writing. 
TABLE OF CONTENTS

ABSTRACT $\ldots \ldots \ldots \ldots \ldots \ldots \ldots \ldots \ldots \ldots \ldots \ldots \ldots \ldots \ldots$

ACKNOWLEDGEMENTS $\ldots \ldots \ldots \ldots \ldots \ldots \ldots \ldots \ldots \ldots \ldots \ldots$

TABLE OF CONTENTS $\ldots \ldots \ldots \ldots \ldots \ldots \ldots \ldots \ldots \ldots \ldots$ iv

LIST OF ILLUSTRATIONS $\ldots \ldots \ldots \ldots \ldots \ldots \ldots \ldots \ldots \ldots \ldots$

CHAPTER ONE

GENERAL INTRODUCTION AND LITERATURE REVIEW . . . . . . . . . 1

I.1 Locust Biology . . . . . . . . . . . . . . . . 2

1.2 Thermoregulation $\ldots \ldots \ldots \ldots \ldots \ldots \ldots \ldots$

1.2.1 Thermoregulation at rest $\ldots \ldots \ldots \ldots \ldots \ldots$

1.2.2 Thermoregulation during flight $\ldots \ldots \ldots \ldots \ldots$

1.3 Wing structure and musculature $\ldots \ldots \ldots \ldots \ldots \ldots$

1.4 Straight flight $\ldots \ldots \ldots \ldots \ldots \ldots \ldots \ldots \ldots \ldots \ldots \ldots \ldots$

1.4.1 Wing kinematics and aerodynamics of straight flight $\ldots \ldots 11$

1.4.2 Aerodynamic models of flight . . . . . . . . . 12

1.4 .3 Motor patterns . . . . . . . . . . . . . 13

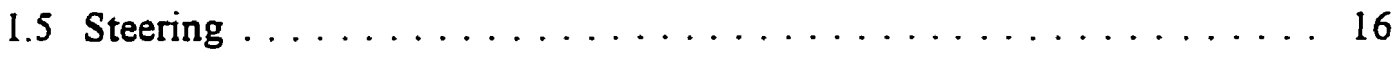


1.5.1 Wing kinematics and aerodynamics of steering . . . . . 17

1.5.2 Motor patterns during steering . . . . . . . . . 18

\section{CHAPTER TWO}

\section{FLIGHT MOTOR PATTERNS OF LOCUSTS}

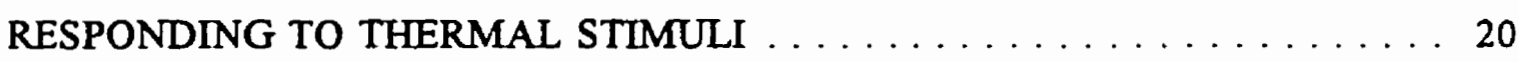

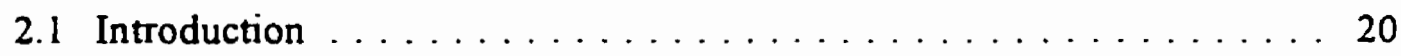

2.2 Materials and Methods . . . . . . . . . . . . . 24

2.2 .1 Animals . . . . . . . . . . . . . . 24

2.2.2 Animal preparation and experimental procedure ...... 24

2.2.3 Electromyographic Analysis . . . . . . . . . . 25

2.2 .4 Videotape Analysis . . . . . . . . . . . . . 28

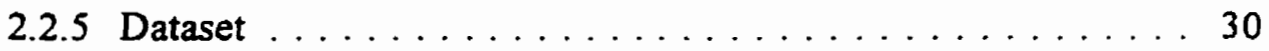

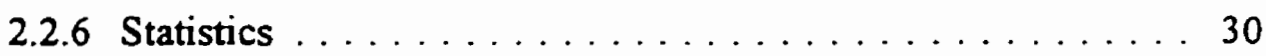

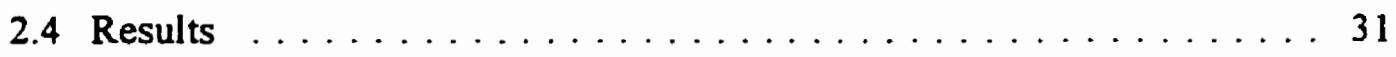

2.4 .1 Behaviour . . . . . . . . . . . . . 31

2.4.2 Muscle m97 activity, abdomen position, and wing angles . . 33

2.4.3 Activity of other downstroke muscle pairs $\ldots \ldots \ldots 39$

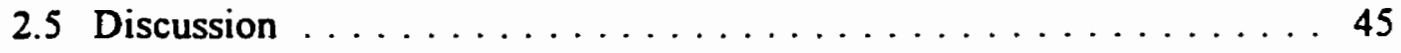

2.5.1 Behaviour . . . . . . . . . . . . 45

2.5.2 Forewing asymmetry and abdomen position $\ldots \ldots \ldots 6$

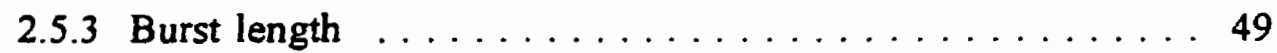


2.5 .4 Wingbeat frequency . . . . . . . . . . . . 50

2.5.5 Motor patterns and proposed model . . . . . . . . . 50

2.5.6 Aerodynamic effect of forewing asymmetry . . . . . . . 54

CHAPTER THREE

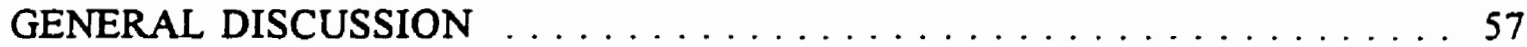

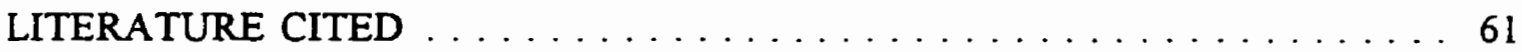

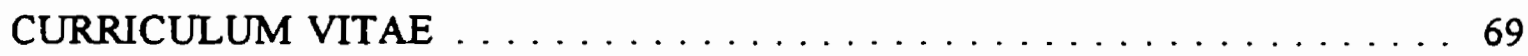




\section{LIST OF ILUUSTRATIONS}

Fig. 1 Thermal budget of locust during flight $\ldots \ldots \ldots \ldots$

Fig. 2 Locust mesothoracic and metathoracic flight musculature. . . . . . . . 9

Fig. 3 Schematic diagram of a cross-section of a locust $\ldots \ldots \ldots \ldots \ldots$

Fig. 4 The relationship between the angular movements of the forewings and hindwings, and the motor pattern of the flight muscles $\ldots \ldots \ldots \ldots 15$

Fig. 5 Drawings of a male locust illustrating electrode placement. . . . . . . . 27

Fig. 6 Steering behaviours attempted by rigidly tethered locusts in response to thermal stimuli

Fig. 7 Changes in $\mathrm{m} 97$ depressor asymmetry and wingbeat frequency in response to a thermal presentation.

Fig. 8 Coincident changes in m97 depressor asymmetry, burst length, forewing asymmetry, and abdomen position for an individual locust at

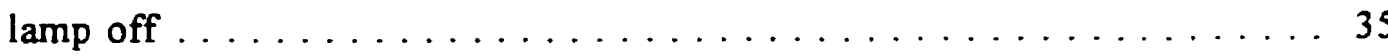

Fig. 9 Changes in burst length that occurred with $\mathrm{m} 97$ asymmetry shifts. . . . 37

Fig. 10 Correlations between the magnitudes of $\mathrm{m} 97$ asymmetry shift, forewing asymmetry (FWA) shift, and abdomen deflection during tethered flight.

Fig. 11 Simultaneous recordings from two pairs of forewing depressor muscles showing similar asymmetry shifts in response to thermal stimuli. 
Fig. 12 Significant positive correlations between asymmetry shifts of pairs of forewing depressor muscles. . . . . . . . . . . . . . . 42

Fig. 13 Simultaneous recordings from pairs of forewing (m97) and hindwing ( $\mathrm{m} 127)$ depressor muscles showing opposite asymmetry shifts in response to thermal presentations $\ldots \ldots \ldots \ldots \ldots \ldots \ldots 44$

Fig. 14 Schematic diagram of motor pattern modulation of depressor muscles during a thermal presentation $\ldots \ldots \ldots \ldots \ldots \ldots \ldots \ldots$ I 


\section{CHAPTER ONE}

\section{GENERAL INTRODUCTION AND LTTERATURE REVIEW}

The behaviour of an animal is constantly modified in response to changing patterns of environmental stimuli. From an analytical standpoint, these changing behaviours can be approached from two different perspectives. At an ultimate level, the adaptive significance of changing behaviour is analysed. Why do animals behave as they do? At a proximate level, the analysis is of development and physiology. What are the physiological mechanisms underlying the changing behaviour?

Considerable research effort has been expended in the search for general principles of motor control. Certainly, all behaviour is controlled by the nervous system. Thus, to elucidate the physiological mechanisms of changing behaviour it is necessary to determine how the activity of the nervous system is modified. Specifically, how does sensory information become integrated within the central circuitry to produce a modified and coordinated motor output? This is a problem successfully solved by the nervous systems of vertebrates and invertebrates alike.

Locust flight provides an excellent model for the study of sensorimotor integration for several reasons. Firstly, the flight behaviour is rhythmic and repetitive, allowing the researcher to acquire abundant data from an individual. Secondly, invertebrates are considered to have simpler nervous systems with fewer neurons than vertebrates, yet many aspects of their functional organization are similar (Pearson 
1993). This relative simplicity makes the locust flight system more tractable than vertebrate motor systems, yet the expectation is that the results will be generally applicable. Finally, flight of a locust involves rigid wings with only a single joint (wing base) and no other moveable parts need be taken into account.

Locust flight is a relatively well-characterized behaviour. In response to external stimuli, the locust steers. Recently, it was found that locusts attempt to avoid a radiant heat source by assuming stereotypical steering postures (Robertson et al. 1996). In Chapter Two, motor patterns during straight flight and in response to thermal stimuli will be analysed. The following literature review will give a background of locust biology and locust flight and steering.

\subsection{Locust Biology}

The African migratory locust, Locusta migratoria, is a species native to Africa (south of the Sahara desert), China, Japan, Philippines, and Australia (for review see Chapman 1976; Uvarov 1966, 1977). They are between four and five centimetres long, with four wings in the adult stage and large hind femora for jumping.

Locusts are grasshoppers, and are morphologically indistinguishable from them. Behaviorally, locusts and grasshoppers are different, because locusts can exist in two distinct phases: solitary and gregarious. In the solitary phase, locusts occur alone and they have no tendency to aggregate. In the gregarious phase, locusts are 
attracted to one another and tend to remain in groups. The phase that they exist in depends on their physical and social environment during their lifespan. If locusts mature in crowded conditions with increased bodily contact they become gregarious. The appearance of the locust is different in each of these phases, both in size and coloration.

In the gregarious phase, locusts have a tendency to swarm, and can travel many hundreds of kilometres. With a swarm size of tens of millions of individuals, they have the capacity to do incredible damage to crops. It is largely because of their economic importance as agricultural pests that their biology has been so wellcharacterized.

\subsection{Thermoregulation}

Maintaining a body temperature within a narrow range is important for animals, mainly because of the temperature dependency of enzymatic reactions. Too low or too high a body temperature can lead to a slowing down of biological processes, which subsequently leads to tissue damage and ultimately death of the organism. It is essential that animals thermoregulate. 


\subsubsection{Thermoregulation at rest}

Terrestrial poikilotherms, such as the locust, face a special challenge in thermoregulation because their body temperatures fluctuate with those of the environment. This can have serious consequences for the poikilotherm, since metabolic rate, food consumption, growth, maturation, adult life-span and communication are all influenced by temperature. However, poikilotherms are not totally at the mercy of their environment. They use behavioral strategies to control internal temperature (for review see Chappell and Whitman 1990; Uvarov 1966).

Through orientation and postural control, the poikilotherm can alter the amount of heat gained through solar radiation, which is the most important factor in heat regulation (Uvarov 1966). By orienting parallel to solar rays, less body surface area is exposed to radiation, and heat gain is minimized. Orienting perpendicular to the sun's rays maximizes heat gain. A basking grasshopper Taenipoda eques may even lie on its side to maximize exposure to radiation at mid-day (Whitman 1987).

Other postural adjustments include crouching and stilting. Crouching describes the posture of the locust when the abdomen and ventral thorax are pressed close to the ground. This posture allows the locust to absorb heat from the substrate and minimize cooling from convective currents. Stilting is a posture assumed when the locust attempts to cool down. The legs are extended to keep the body high off the substrate. Crouching and stilting are highly effective in temperature control. Chappell (1983) found that in the grasshopper Trimerotropis pallidipennis, the 
thoracic temperature difference in the crouched or stilted positions could be as large as $10^{\circ} \mathrm{C}$.

To thermoregulate, locusts can also physically move to a different microclimate, since they are small and mobile. Normally, this movement occurs cyclically during the day. At sunrise and sunset, the locust may bask on plants, while at mid-day they move down into the denser and cooler vegetation (Whitman 1987).

\subsubsection{Thermoregulation during flight}

Thermoregulation during flight is a special problem faced by larger insects. In order for the wings to generate lift, the thoracic muscles controlling the wings must be within a relatively narrow temperature range. For locusts this range is between $25^{\circ} \mathrm{C}$ and $40^{\circ} \mathrm{C}$ (Weis-Fogh 1964). However, once the locust is airborne, the flight muscles generate excess heat that must be dissipated if flight is to be maintained. At the very least, the locust must lose as much heat as the muscles produce. There are many factors that influence thoracic temperatures during flight (Fig. 1).

The main source of heat gain is radiation, and the main source of heat loss is through convection (Uvarov 1966). This balance however, can vary depending on weather and time of day. On a cloudy day, or at sunrise or sunset, the heat gain by radiation is reduced (for review see Rainey 1974). Heat loss by convective currents is also variable depending on air temperature, air density, and air speed. 
Fig. 1 Thermal budget of locust during flight (Rainey 1974). 


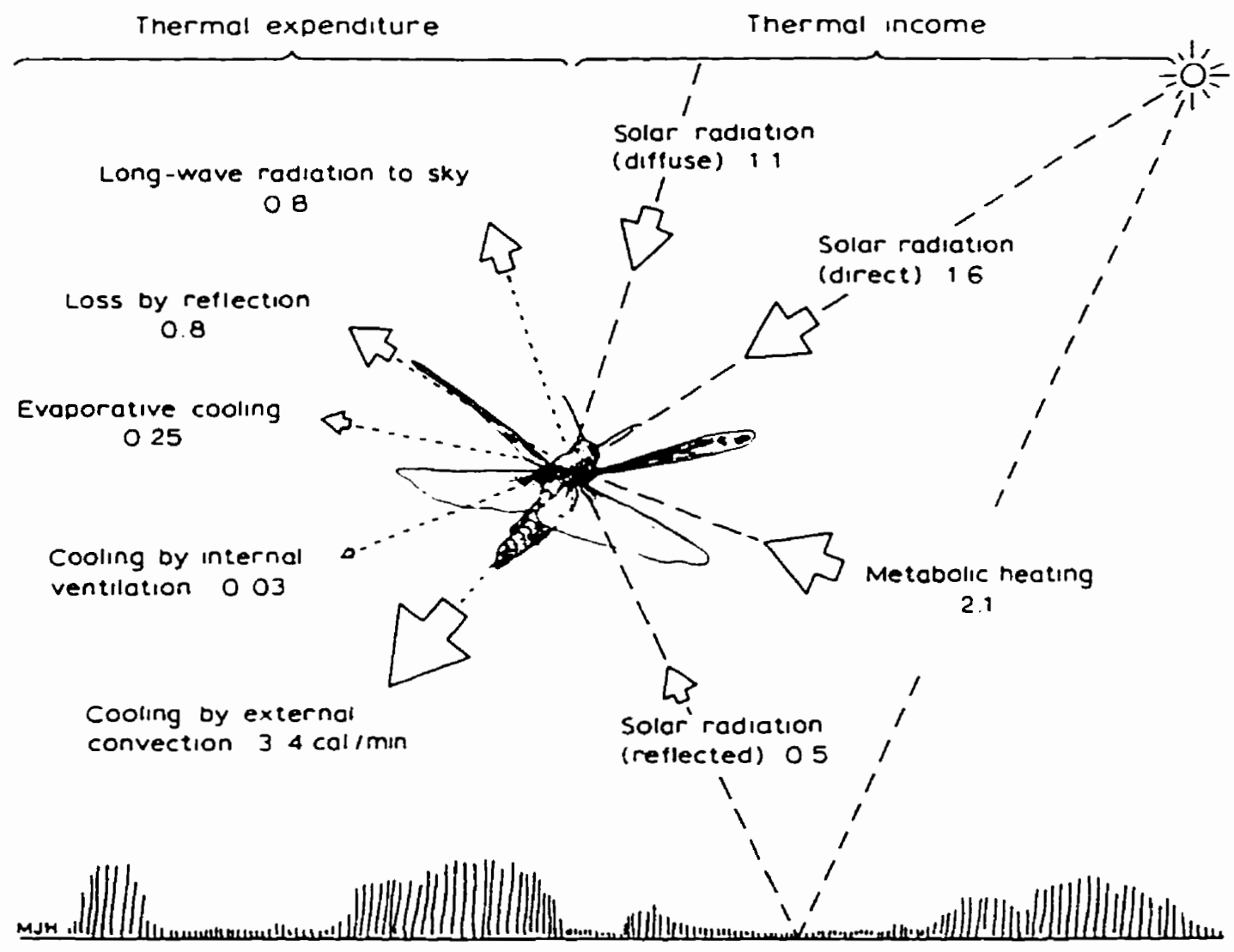


An interesting factor involved in cooling off the locust is evaporative cooling by rain. Raindrops falling on locusts that have a thoracic temperature higher than that of the ambient temperature will evaporate, and this has been shown to cool the flying locust down to a temperature of $22^{\circ} \mathrm{C}$ (Waloff and Rainey 1951 as cited in Rainey 1974). At this low thoracic temperature, flight cannot be maintained, and the locust must land.

\subsection{Wing structure and musculature}

Wings are the living integumental outgrowths of the insect meso- and metathorax. They are intricate in structure, containing veins, which are hollow tubes that contain blood, nerves, and tubes for air. At the base of the wing veins are axillary sclerites which articulate with the thorax (for review see Evans 1984).

Flight in locusts is generated by the flapping of all four wings. The control of wing movement is generated by the alternating activity of elevator and depressor muscles, and these muscles can be divided into three categories: direct flight muscles, indirect flight muscles, and accessory muscles.

Direct flight muscles have attachment sites at the wing base, and when they contract, the wing is pulled down. Two direct downstroke muscles, the basalar and the subalar, provide power for the downstroke and also control wing twisting. In the 
locust, each wing has three direct depressor muscles that are numbered according to Snodgrass (1929). Muscles $\mathrm{m} 97$ and $\mathrm{m} 98$ are the forewing first and second basalars, respectively. Muscles $\mathrm{ml} 27$ and $\mathrm{ml} 28$ are the hindwing first and second basalars, respectively. Muscle $\mathrm{m} 99$ is the forewing subalar, and $\mathrm{ml} 29$ is the hindwing subalar (Fig. 2).

Indirect flight muscles do not act on the wing directly at the wing base, but instead cause wing movements through the deformation of the thorax. The indirect elevator muscles act by displacing the tergum ventrally (Fig. 3). Through a series of stress interactions between the ligaments and the wing hinge, the wing goes up. The energy stored in the elastic hinges during the upstroke is released during the downstroke and provides a bulk of the downstroke force.

The indirect depressor muscles are the dorsolongitudinal muscles. Their contraction deforms the thorax by pushing the tergum dorsally, which in turn pushes the wing down (Fig. 3).

An accessory muscle of the forewing is the pleuroaxillary muscle ( $\mathrm{m} 85)$. Based on recent evidence, this muscle does not cause wing depression, but only acts towards wing twisting by counteracting the effects of pronator muscles (Elson and Pflüger 1986; Wolf 1990). 
Fig. 2 Locust mesothoracic and metathoracic flight musculature. A Elevator muscles. B Depressor muscles (Wilson and Weis-Fogh 1962). 

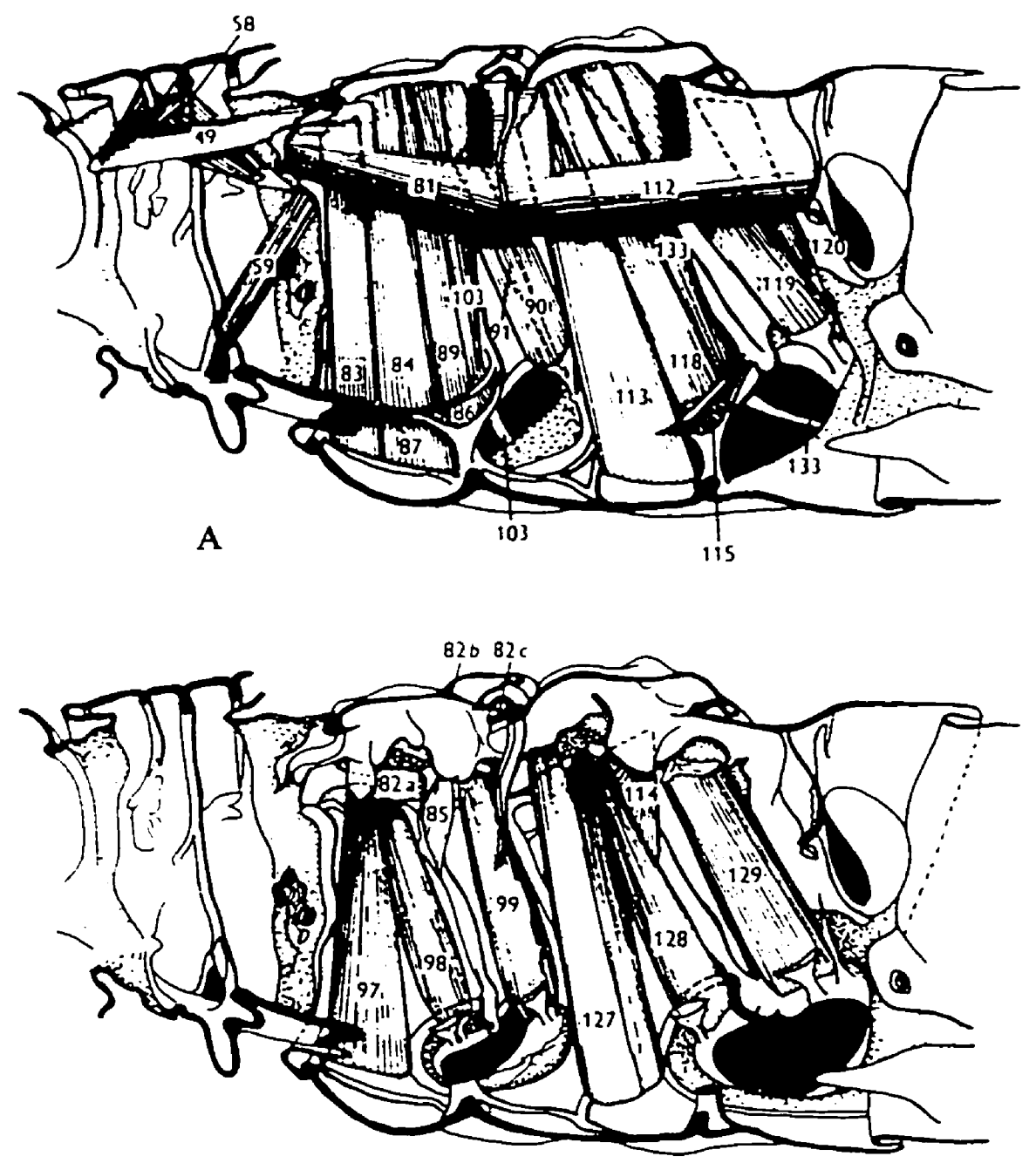

B

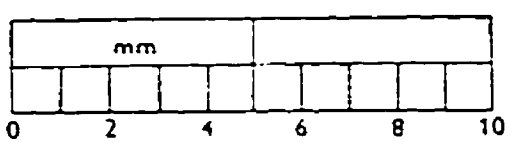


Fig. 3 Schematic diagram of a cross-section of a locust at the level of the wing hinge illustrating the action of indirect flight muscles. Dorsal is top. Indirect elevator muscles act by distorting the thorax and pulling the tergum ventrally (dotted lines).

Indirect depressor muscles act by distorting the thorax and pushing the tergum dorsally (solid line). The stresses generated by the distorted thorax on the wing hinge cause the wings to move (modified from Weis-Fogh 1956). 


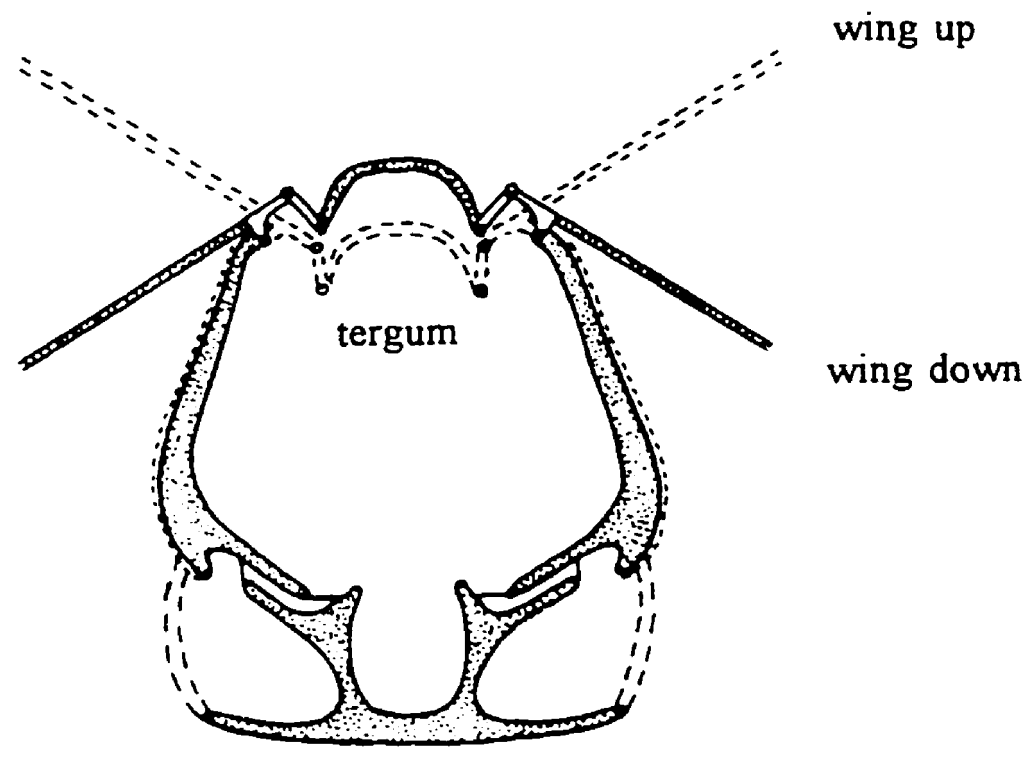




\subsection{Straight night}

\subsubsection{Wing kinematics and aerodynamics of straight flight}

During flight, locusts assume a stereotypical flight posture. The antennae are forward, the abdomen held up, and the hindlegs are folded in so that the tibiae rest against the femora. The wings are frequency-coupled, meaning that the number of wingbeats each second is identical in the forewings and hindwings. The wings are not phase coupled, meaning that the forewings and hindwings do not start the upstroke and downstroke together. The hindwings always lead the forewings in locust flight by 5 to $10 \mathrm{~ms}$ (for review see Weis-Fogh 1956).

During free-flight, the locust can regulate translational forces in three different directions. Lift is a vertical force, in which the locust's centre of gravity is propelled upwards. Thrust is a forward force, in which the entire body is propelled forward. Side-slip is an unbalanced force which produces translational movements of the locust to the right or left. In order for steady forward flight to be maintained, lift must equal body weight, and thrust must equal drag.

During flight it is imperative that the aerodynamic effects of the upstroke and downstroke do not cancel one another. In other words, if the upstroke and downstroke generated equal but opposite forces, the animal would never lift off the ground. The locust handles this challenge by adjusting the wing angle of attack, or wing twisting, on the upstroke and downstroke relative to the wind. By altering the 
degree of wing twisting relative to the windstream, lift and thrust can be controlled (Weis-Fogh 1956). In the downstroke, the wings are slightly pronated (leading edge twisted downward). In the upstroke, the wings are supinated (leading edge twisted upward). By increasing pronation during the downstroke, lift can be decreased. By decreasing pronation, lift can be increased.

\subsubsection{Aerodynamic models of flight}

The conventional aerodynamic model was proposed by Jensen (1956) and was based on the principles of steady state aerodynamics. Steady state aerodynamics describe the forces generated by a stationary aerofoil, such as an airplane wing. The wing travels at a constant velocity through the air, and due to the air circulation pattern around the wing, lift is produced. Steady-state aerodynamics do not apply to flapping flight because the wings are not steady, but instead are constantly changing direction and velocity during upstrokes and downstrokes. Jensen estimated the aerodynamic forces of flight by calculating the forces exerted at successive instants during the stroke. From instantaneous forces, Jensen estimated the forces generated by the wingstroke as a whole. This type of analysis has been termed quasi-steady analysis, and is sufficient to explain forces produced during fast forward flight. The forces calculated by quasi-steady analysis may be too conservative in some instances to explain the large lift production by some animals. Weis-Fogh 
(1973) proposed a novel mechanism for hovering flight to explain the source of the extra lift. This mechanism is called the clap and fling. The clap occurs at the top of the downstroke, when the leading edge of the wings are brought together. The fling occurs immediately following the clap at the top of the downstroke. The wings quickly twist into a pronated position, described as being like opening the pages of a book. The airflow generated around the wings at the time of the fling creates circulation around the wings and generates lift. This mechanism is used by pigeons during takeoff, and explains the loud clapping noise that is heard. The clap and fling mechanism has also been used to explain takeoff in Locusta (Cooter and Baker 1977). Ellington (1984) also recognized that calculated quasi-steady forces were insufficient to explain the lift generated in some flyers, and proposed that vortex circulation of the air around the wings could provide a new answer for the extra source of the lift. More recently, Ellington et al. (1996) observed such vortices in the hovering flight of Manduca, and through mathematical analysis, confirmed that the forces generated by vortices are sufficient to maintain this insect in the air.

\subsubsection{Motor patterns}

The forces generated by the wings are products of the underlying flight motor pattern. Insect flight muscles can be neurogenic or myogenic. Myogenic flight muscles are also known as asynchronous flight muscles, because muscle contractions 
are not synchronous with motor neuron activity. Instead, muscle contraction is initiated by stretching.

Locusts possess neurogenic flight muscle, in which each muscle contraction is stimulated by a separate motor neuron impulse (for review see Kammer 1985). Because locusts are neurogenic flyers, motor neuron activity can basically be studied through flight muscle electromyographic (EMG) analysis.

During straight flight, the hindwing basalars ( $\mathrm{ml} 27$ and $\mathrm{ml} 28$ ) and subalar (m129) fire earlier during the downstroke than the forewing direct depressor muscles (Fig. 4) (Wilson and Weis-Fogh 1962). This corresponds to the earlier hindwing depression. Of the forewing direct depressors, $\mathrm{m} 97$ is the first to fire, and although it is capable of firing triple spikes (Waldron 1967) during straight flight it fires singlets or doublets (Wilson and Weis-Fogh 1962). The second muscle to fire, according to Wilson and Weis-Fogh (1962) is either m98 or m99. No literature could be found on when $\mathrm{m} 85$ was active during this sequence of events, but normally during straight flight it produces a single spike per wingbeat (Elson and Pflüger 1986).

The action of muscles $\mathrm{m} 97, \mathrm{~m} 98$ and $\mathrm{m} 127$ are to not only depress the wings, but to pronate the wing also. Muscle $\mathrm{m} 85$ is believed to counteract pronation during the downstroke (Elson and Pflüger 1986; Wolf 1990) and thus increase angle of attack.

Muscle $\mathrm{m} 99$ is a direct depressor, yet its role in setting the angle of attack is uncertain. Wilson and Weis-Fogh (1962) postulated that m99 was a supinator, because it increased its activity during periods of increased angle of attack. Zarnack 
Fig. 4 The relationship between the angular movements of the forewings and hindwings, and the motor pattern of the flight muscles. The muscles of interest in Chapter Two include $\mathrm{m} 97, \mathrm{~m} 98, \mathrm{~m} 99$, and $\mathrm{m} 127$. Each motor unit is represented by a horizontal line. The small dot symbol $(\bullet)$ indicates the timing of muscle firing. The heavy bar for m99 activity indicates that it fires within that particular range (modified from Wilson and Weis-Fogh 1962). 


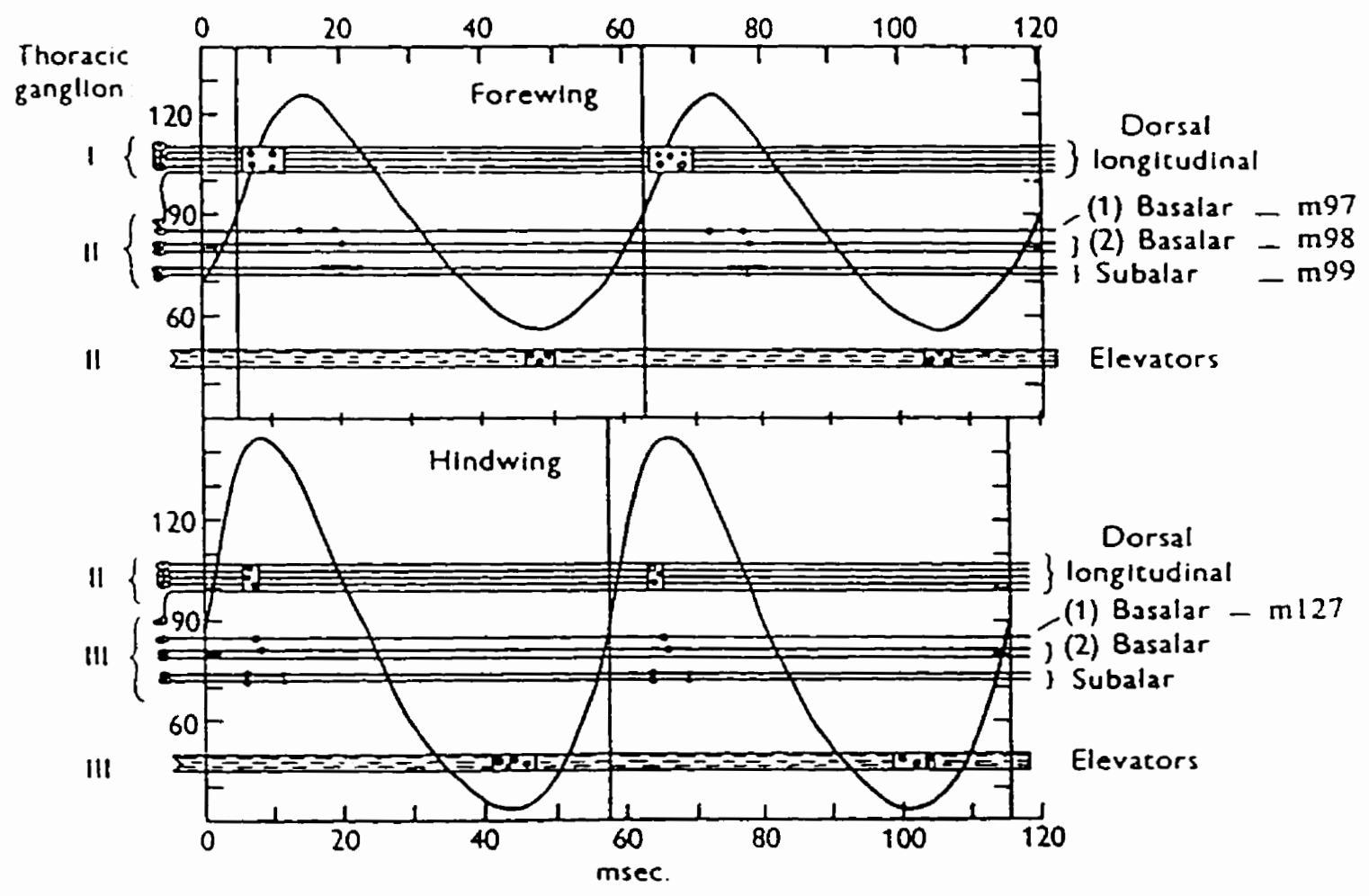


(1988) found a decreased angle of attack with increased m99 activity.

\subsection{Steening}

Two types of steering are evident in locusts. Correctional steering occurs when the locust is attempting to maintain a straight course. Any deviations due to turbulence or motor errors are quickly corrected for. Intentional steering occurs when the locust changes flight direction in response to an external stimulus, such as an obstacle in the flight path.

Steering can occur in three directions. Pitch corresponds to a rotation in the vertical plane, in which the head rotates to be higher or lower than the body's centre of gravity. Yaw is the horizontal rotation of the body about the dorso-ventral axis, in which the head is left or right of the abdomen. Roll is a rotation along the dorsolongitudinal axis of the body.

Baker (1979a) discusses the relationship between roll and yaw, and found in steering experiments that the behavioral changes in each manoeuvre were the same. The locust, instead of isolating roll and yaw, probably makes a banked turn. Because of this prediction, roll and yaw will be considered together here. Pitch will not be discussed. 


\subsubsection{Wing kinematics and aerodynamics of steering}

During steering, there are many changes that are observed in the flying locust. It is generally agreed that the abdomen deflects into the direction of the turn, and that the hind leg on the inside of the turn extends (Camhi 1970; Arbas 1986). There are also head movements associated with both correctional and intentional steering (Camhi 1970; Robert and Rowell 1992). Additionally, wing kinematics are altered in yaw and roll turns in order to decrease lift and thrust on the inside of the turn and increase lift and thrust on the outside of the turn. However, between correctional and intentional steering, there is disagreement about which kinematic parameter is most important.

In correctional steering studies in which kinematic analyses were performed, the importance of angle of attack was stressed (Zarnack 1988; Waldmann and Zarnack 1988). Although changes in timing of downstroke phasing were also found, their importance was diminished or no aerodynamic consequence was discussed (Thüring 1986; Waldmann and Zarnack 1988). Also, during intentional steering to asymmetrical lighting, angles of pronation and supination were stressed (Dugard 1967; Baker 1979a). In all of these studies, the increased angle of pronation was on the inside of the attempted turn. This would result in decreased lift on that side of the body and a banked turn.

During responses to "urgent" stimuli, such as the call of an echolocating bat, an obstacle in the flight path, or radiant heat, the most profound kinematic parameter 
is the generation of forewing asymmetries during the downstroke (Robertson and Reye 1992; Robertson and Johnson 1993; Robertson et al. 1996; Dawson et al. 1997). This forewing asymmetry (FWA) refers to the different elevation angles on either side of the body. Often, the asymmetry in elevation is so large that the forewing on the inside of the attempted turn is more depressed than the ipsilateral hindwing. Although aerodynamic studies have not been performed on the forces generated by FWA, it is predicted that the resultant lift vector will be inclined in the direction of the most depressed forewing, and a banked turn will result (Dawson et al. 1997).

\subsubsection{Motor patterns during steering}

Because the wing movements are controlled by flight muscles, and asymmetrical kinematic parameters are necessary for steering, then it would be expected that some aspect of the flight motor pattern would also be asymmetrical.

All researchers of correctional and intentional steering motor patterns have found asymmetries in muscle activity. A general trend in correctional steering is that no changes in the number of muscle potentials per burst occur (Thüring 1986; Waldmann and Zarnack 1988; Zarnack 1988). There was an observation that there was a change in the activation time of the direct depressor muscles of the forewing. On the side ipsilateral to the turn, all direct depressors fired earlier than their corresponding contralateral muscles (Thüring 1986; Waldmann and Zarnack 1988). 
Elson and Pflüger (1986) found similar timing shifts in $\mathrm{m} 85$.

In intentional steering, changes in burst length have been reported in $\mathrm{m} 97$ (Dugard 1967; Baker 1979b; Robertson et al. 1996; Dawson et al. 1997).

Additionally, the increased burst length in $\mathrm{m} 97$ was associated with earlier onset of activation.

Baker (1979b) found shifts of $12 \mathrm{~ms}$ in $\mathrm{m} 97$ and found variation between ipsilateral $\mathrm{m} 97$ and $\mathrm{m} 98$. Muscle $\mathrm{m} 99$ showed little asymmetry on left and right sides during steering. Apart from this study, no attempt has been made to analyse motor patterns of intentional steering. Particularly, no attempt has been made to determine the motor pattern required for FWA. 
CHAPTER TWO

\section{FLIGHT MOTOR PATTERNS OF LOCUSTS RESPONDING TO THERMAL STIMULI}

\subsection{Introduction}

Two types of steering have been described in locusts: correctional steering and intentional steering (for review see Kammer 1985; Rowell 1988). Correctional steering allows the locust to maintain a straight course in the face of environmental perturbations or motor errors. In simplistic terms, correctional steering can be thought of as an "autopilot" by which reflexes act to compensate for involuntary deviation from course. Intentional steering occurs when the locust turns in response to internal motivation or external stimuli, such as those which may be dangerous (e.g. an obstacle in the flight path) or alluring (e.g. a potential food source). Intentional steering, often described as a tendency to turn, must involve eliminating correctional reflexes, i.e. disabling the autopilot (Robert and Rowell 1992).

Superficially, the behaviours associated with intentional and correctional steering are similar. The hindleg ipsilateral to the turn extends, and the abdomen rudders into the direction of the tum (Camhi 1970; Arbas 1986; Robert 1989). In terms of wing kinematics, several asymmetries become apparent, including changes in the angle of attack on left and right sides, changes in stroke amplitude, and phase 
changes in the timing of depression (for review see Rowell 1988).

A closer look at these behaviours reveals that correctional and intentional steering are different. Camhi (1970), in a comparison of the two types of steering, noted that different abdominal segments are involved in the two steering types. Both Camhi (1970) and Robert and Rowell (1992) noted that head movements are different between the two types of steering. Robert and Rowell (1992) found that during correctional steering, head movements are directed into the turn, while in an intentional steering manoeuvre the head moves in a direction opposite that of the turn.

A further difference between intentional and corrective steering is that the former results in the generation of profound forewing asymmetries (FWA) of elevation angle during the downstroke that are not obvious in the latter (Robertson and Reye 1992). For example, during an intentional turn to the right, the right forewing is more depressed than the left during the downstroke. Often, this asymmetry is so large that during the downstroke the forewing is more depressed than the hindwing on the side of the body ipsilateral to the turn. FWA changes have been observed during attempted steering manoeuvres in response to objects approaching in the flight path (Robertson and Reye 1992; Robertson and Johnson 1993), laterallyplaced heat stimuli (Robertson et al. 1996), and auditory stimuli mimicking the calls of echolocating bats (Dawson et al. 1997).

There is considerable information available about correctional motor patterns (Zarnack and Möhl 1977; Thüring 1986; Waldmann and Zarnack 1988), but relatively little about the motor patterns that underlie intentional steering manoeuvres, 
particularly the FWA. The general goal of this study was to describe the motor pattern for the FWA to facilitate future studies of the mechanisms by which sensory information is integrated with the activity of the flight circuitry.

Dawson et al. (1997) show that forewing asymmetry during the downstroke can be generated by changing the relative timing of stroke reversals at the top of the upstroke. This would effectively cause one forewing to lead the other during the downstroke. To change the timing of stroke reversal, it is necessary that the time of contraction of muscles controlling stroke reversal be modified and it was suggested that "bulk shifts" in depressor muscle activity may be required to generate FWA. These bulk shifts refer to the advancement of timing of all forewing depressor muscles (m97, $\mathrm{m} 98, \mathrm{~m} 99, \mathrm{~m} 85)$ on one side of the body relative to their corresponding contralateral muscles.

Bulk shifts have been reported in correctional steering manoeuvres (Thüring 1986; Waldmann and Zarnack 1988; Zarnack 1988) yet these bulk shifts have only been loosely correlated with phase-shifts of stroke reversal timing for left and right sides. Additionally, despite these bulk shifts, Zarnack (1988) and Waldmann and Zarnack (1988) stress that changing the angle of attack is the crucial element for steering manoeuvres. Our specific goal was to test the hypothesis that the FWA is strongly correlated with bulk shifts in the timing of forewing depressor muscle activity.

Using thermal presentations as stimuli to induce steering, we simultaneously recorded flight muscle activity from two contralateral muscle pairs and videotaped 
postural and wing kinematic behaviour. Thermal stimuli were used because it has already been established that thermal stimuli generate intentional steering manoeuvres including the FWA (Robertson et al. 1996), and that the responses observed are several seconds in duration. We found that forewing asymmetries and m97 activity shifts are strongly and positively correlated. An earlier firing of $\mathrm{m} 97$ is associated with a greater wing depression during the downstroke. Additionally, we found that shifts in muscle timing of other forewing depressor muscles are similar in direction and magnitude as those observed in $\mathrm{m} 97$. These findings support the contention that large asymmetries in the elevation angle of the forewings during the downstroke, such as are evident during intentional steering, are generated by bulk shifts in the activation times of forewing depressor muscles to cause a relative shift in the time of stroke reversals of the two forewings. 


\subsection{Materials and Methods}

\subsubsection{Animals}

Adult male Locusta migratoria L. at least two weeks past the adult moult were used. Locusts were collected from a crowded colony (light:dark cycle of 16:8 hours) maintained at Queen's University. Males were selected for these experiments to reduce variability in the magnitude of manoeuvres associated with the size difference between males and females.

\subsubsection{Animal preparation and experimental procedure}

Each animal was blinded and deafened before a flight sequence to ensure that the attempted steering responses were not in response to visual or auditory cues. Compound eyes and ocelli were covered with opaque ceramic paint, taking care not to cover surrounding areas of cuticle. To deafen the animal, both tympanic membranes were destroyed using an insect pin. Additionally, all six legs were removed at the coxa-trochanter joint so that the animal could not grasp either the electrodes or the tether. Removing the legs is a treatment that has been used by various researchers of locust flight and steering (Wilson and Weis-Fogh 1962; Camhi 1970; Taylor 1981; Baader 1990) and has no noticeable effects on steering behaviour. 
Animals were dorsally tethered by affixing a rod to the pronotum with wax and then were suspended in a windstream (air speed approximately $3 \mathrm{~m} / \mathrm{s}$ ). Care was taken during tethering to ensure that the animal was straight, and thus reduce potential steering biases to asymmetrical wind stimulation of the head. Four EMG electrodes were implanted (see below). The animals were allowed to fly uninterrupted until the abdomen was in line with the dorso-longitudinal axis of the thorax, usually about two minutes. Once steady tethered flight was achieved, a 250 Watt heat lamp, placed 7.5 $\mathrm{cm}$ to the left or right of the animal, was turned on. Thermal presentations usually lasted between 9 and 14 seconds, but could be shorter or longer depending on the response time of the animal. The timing of thermal presentations was monitored with a Sensortek thermometer (model BAT-12, Clifton, NJ, USA) with a copper/constantan thermocouple placed $1 \mathrm{~cm}$ above the locust's head. Thermocouple output was an indication of stimulus timing only, and for this reason, the thermocouple output was not converted to degrees celsius from the voltage change produced by the device.

Although a second stimulus was usually presented, only responses to first stimuli were analysed. This was done to avoid the possibility of analysing smaller, habituated responses.

\subsubsection{Electromyographic Analysis}

Four electromyographic (EMG) electrodes, consisting of fine copper wire (100 
$\mu \mathrm{m}$ in diameter) and insulated except at the tip, were inserted into two downstroke muscle pairs through small holes made in the cuticle. These insertion points were on either the ventral or pleural surface of the body, depending on the muscles selected (Fig. 5). Each electrode was held in place with a small drop of wax. A fifth indifferent silver electrode was inserted beneath the pronotum behind the head.

From every animal in the dataset, we recorded activity of left and right forewing first basalar muscles (m97). The second pair of electrodes recorded from either the forewing pleuroalar muscles (m85), the forewing second basalar muscles (m98), the forewing subalar muscles (m99) or the hindwing first basalar muscles (m127) (nomenclature according to Snodgrass 1929).

Signals from the EMG electrodes were first amplified, and then recorded onto VHS videotape using a Neuro-corder (model DR-886, Delaware Water Gap, PA, USA). The instantaneous timing of muscle activity was analysed using hardware and software from Datawave Technologies (Longmont, CO, USA). Three separate elements of the flight motor pattern were calculated from the digitized time values. 1) We measured depressor asymmetry, which is the difference in the activation time of homologous contralateral motor units. It is calculated by subtracting the right muscle activation time from that of the left. A positive depressor asymmetry indicated that the right muscle was firing earlier in the wingbeat cycle than the left. 2) We measured the muscle timing relationships on a single side of the body by subtracting $\mathrm{m} 85, \mathrm{~m} 98, \mathrm{~m} 99$, or $\mathrm{m} 127$ timing from $\mathrm{m} 97$ timing. A negative relationship between $\mathrm{m} 85$ and $\mathrm{m} 97$ indicated that $\mathrm{m} 97$ fired first. 3) We determined 
Fig. 5 Drawings of a male locust illustrating electrode placement. A Side view of a locust showing electrode positions for $\mathrm{m} 85, \mathrm{~m} 98$, and $\mathrm{m} 99$. The electrode placement for $\mathrm{m} 85$ is just beneath the edge of the forewing. B Ventral view of a locust showing electrode positions for $\mathrm{m} 97$ and $\mathrm{m} 127$. Note that these insertion points are on the callosities, which are regions of bare cuticle. The length of the male locust, from top of head to tip of abdomen, is between 4 and $5 \mathrm{~cm}$. 

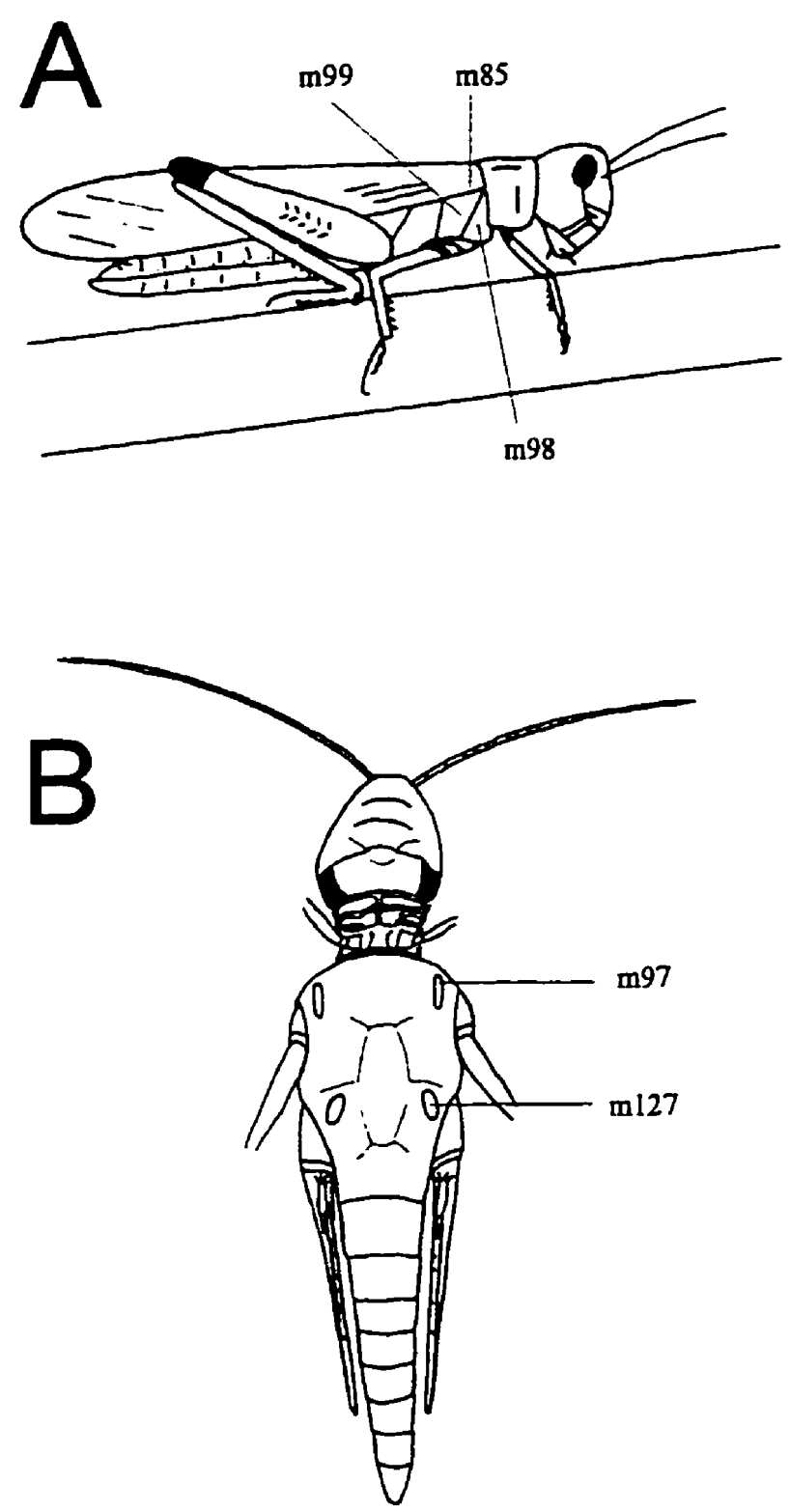
the burst length of $\mathrm{m} 97$ during thermal presentations. Burst length is defined as the number of muscle potentials occurring during each muscle contraction.

Following each experiment, electrodes were cut, leaving the ends of the electrode wires within the animal. Electrode placement was confirmed by postmortem dissection. This was done by first injecting the animal with $\mathrm{lmL}$ fixative (1:4 95\% ethanol : $99.7 \%$ acetic acid). The following day, animals were dissected by first removing the head, and completely bisecting the animal along the dorso-longitudinal axis to separate left and right sides. Without disrupting the natural curve of the pleural cuticle, the flight muscles were then exposed. The elevator muscles were removed to reveal the underlying depressor muscles, and electrode placement was determined by careful dissection until the electrode was seen.

\subsubsection{Videotape Analysis}

During flight sequences, animals were videotaped from behind (Hitachi 5200A video camera, electronic shutter speed $1 / 1000$ s) so that we could later calculate abdomen position and wing elevations. Using hardware and software manufactured by PEAK Performance Technologies Inc. (Englewood, CO, USA), we conducted a frame-by-frame analysis of approximately 350 frames encompassing a stimulus response. We refer to a stimulus response as one occurring either to the light turning on or the light turning off (hereafter referred to as either lamp on or lamp off). For 
each frame we marked the positions of the top and bottom of the tether, each wing tip, and the tip of the abdomen. The marked pixel coordinates were then used to calculate, for every frame, the angle between each wing and the line of the tether. Lateral deflection of the abdomen was also calculated.

Usually, in response to a stimulus, the abdomen reached its full deflection in less than two seconds. We monitored 350 frames ( 5.6 seconds) to ensure that we captured the entire pre-stimulus and post-stimulus wing and abdomen response.

From the calculated wing angles we determined forewing asymmetry (FWA), which is the difference between the angles of the forewings during the downstroke. FWA was calculated by subtracting the angle of the left wing from the angle of the right wing. Since $0^{\circ}$ indicates directly above the animal and $180^{\circ}$ is directly below, a positive FWA indicated that the right wing was more depressed than the left during the downstroke. Since hindwings lead forewings during the downstroke (Wilson and Weis-Fogh 1962), downstroke frames were determined when the hindwing was more depressed than the forewing on the outside of the turn. Because we wanted to correlate muscle activity with wing movements, and because the depressor muscles fire at the top of the downstroke (Wilson and Weis-Fogh 1962), we selected for analysis only those downstroke frames in which the forewing on the outside of the turn was between $0^{\circ}$ and $80^{\circ}$. 


\subsubsection{Dataset}

Recordings were taken from ninety-one male locusts, however 57 were removed from the dataset due to excessive crosstalk between recording electrodes, subsequent determination that the wrong muscle had been recorded, or because the animals did not fly continuously. Of the remaining 34 locusts, 20 were used for analysis of activity in $\mathrm{m} 97$ and $\mathrm{m} 127$ muscle pairs. Four locusts were used to analyse activity in $\mathrm{m} 97$ and $\mathrm{m} 85$ muscle pairs. Five were used to analyse activity in $\mathrm{m} 97$ and m98 muscle pairs. Five were used to analyse activity in $\mathrm{m} 97$ and $\mathrm{m} 99$ muscle pairs.

\subsubsection{Statistics}

We used SigmaStat ${ }^{\star}$ statistical software (Jandel Corporation, San Raphael, CA, USA) to conduct appropriate parametric and non-parametric tests. Significance was assumed when $P<0.05$. 


\subsection{Results}

\subsubsection{Behaviour}

When the wind tunnel was tumed on, most locusts began to beat their wings. Others required additional stimulation, and a quick pinch of the abdomen with forceps usually sufficed. At the beginning of these flight sequences the abdomen position was not constant, and only after approximately two minutes did the abdomen finally settle in a position in line with the dorso-longitudinal axis of the thorax. Once the locust was maintaining straight and steady flight, the thermal stimulus was presented. The abdominal response for 33 locusts to thermal stimuli varied (Fig. 6). Ten of 33 animals $(30.3 \%)$ deflected their abdomens away from the heat lamp when it was turned on. Ten of $33(30.3 \%)$ did not respond to the lamp on, but did respond to lamp off by deflecting their abdomens towards the direction of the lamp. Another 10 animals (30.3\%) performed both of these manoeuvres: they deflected their abdomens away from lamp on, and towards the heat lamp at lamp off. Although a majority of the animals did not attempt to steer directly towards an illuminated heat lamp, there were 3 that did $(9.1 \%)$. Two of these three only responded when the heat lamp was turned on. One animal turned towards the heat lamp both at the beginning and immediately following the stimulus. 
Fig. 6 Steering behaviours attempted by rigidly tethered locusts in response to thermal stimuli. The behaviours described here are in response to first stimulus presentations, and direction of steering was based on direction of abdomen deflection. 


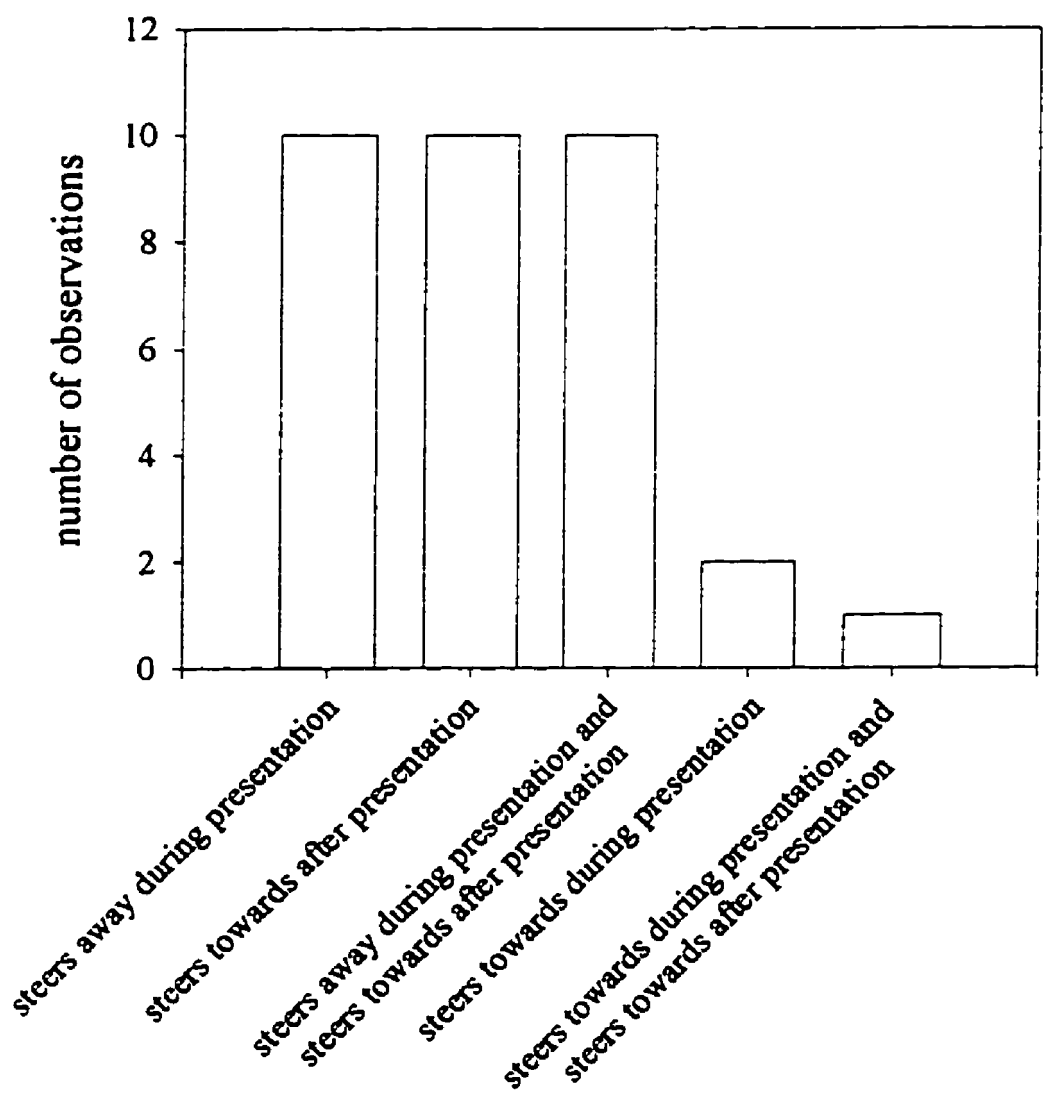


2.4.2 Muscle m97 activity, abdomen position, and wing angles

Muscle activity of $\mathrm{m} 97$ was monitored from every animal, and the asymmetry in $\mathrm{m} 97$ activity between left and right sides shifted in response to thermal stimuli. These m97 asymmetry shifts were sometimes gradual, progressing over several seconds, or they could be abrupt. Often the abrupt responses occurred at lamp off (eg. Fig. 7). This individual showed little change in $\mathrm{m} 97$ asymmetry at stimulus onset (monitored by thermocouple output), but at lamp off, a large positive m97 asymmetry shifts of more than $10 \mathrm{~ms}$ occurred. At both lamp on and lamp off, wingbeat frequency increased, indicating that the locust detected the stimulus at both of these times. Of 34 responses from 34 animals, 28 (82\%) showed significant increases in WBF in response to lamp on or lamp off (paired $t$-test, $t=-4.8, P<0.05$, $\mathrm{n}=34$ ). The average WBF before steering was $20.0 \pm 0.4 \mathrm{~Hz}$ (mean \pm s.e.m.). The average increase in WBF during the steering manoeuvre was $1.3 \pm 0.3 \mathrm{~Hz}$ (mean \pm s.e.m.).

For 25 of the locusts, we determined the wing angles and abdomen positions during the steering response. 350 video frames $(5.6$ seconds) were analysed from each flight sequence. The calculated forewing asymmetry (FWA: right wing angle minus left wing angle) was time-aligned with abdomen position and electromyographically recorded $\mathrm{m} 97$ activity ( $\mathrm{L}-\mathrm{R}$ asymmetry and burst length). In Fig. 8, in response to lamp off, there was a negative m97 asymmetry shift, and increased burst length in the left $\mathrm{m} 97$ and a decreased burst length in the right $\mathrm{m} 97$. 
Fig. 7 Changes in $\mathrm{m} 97$ depressor asymmetry and wingbeat frequency in response to a thermal presentation. These data are from an individual locust that attempted a right turn to lamp off. The shaded bar indicates presentation of thermal stimulus based on thermocouple output (bottom trace). In subsequent figures, the shaded bar alone indicates stimulus presentations. A positive depressor asymmetry shift occurred when the heat lamp was turned off (top trace), indicating that the right m97 was firing before the left. Note also that at both lamp on and lamp off there was an increase in wingbeat frequency (middle trace). 


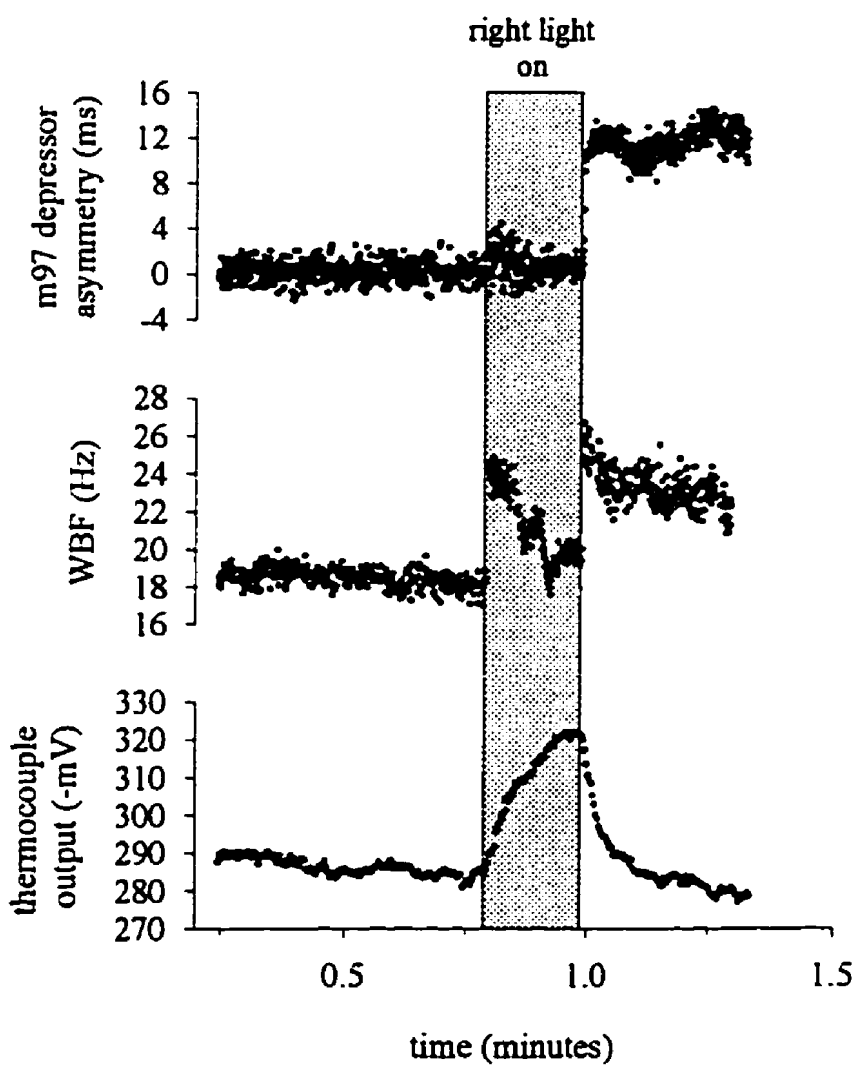


Fig. 8 Coincident changes in m97 depressor asymmetry, burst length, forewing asymmetry, and abdomen position for an individual locust at lamp off. $\mathbf{A}$ When the left heat lamp was turned off, there was a negative m97 depressor asymmetry shift, indicating that the left muscle shifted to fire before the right. B The average burst length of the left $\mathrm{m} 97$ increased at lamp off. C The average burst length of the right m97 decreased at lamp off. D There was a negative shift in forewing asymmetry, indicating that the left forewing was more depressed that the right during the downstroke. E The abdomen deflected to the left at lamp off. 

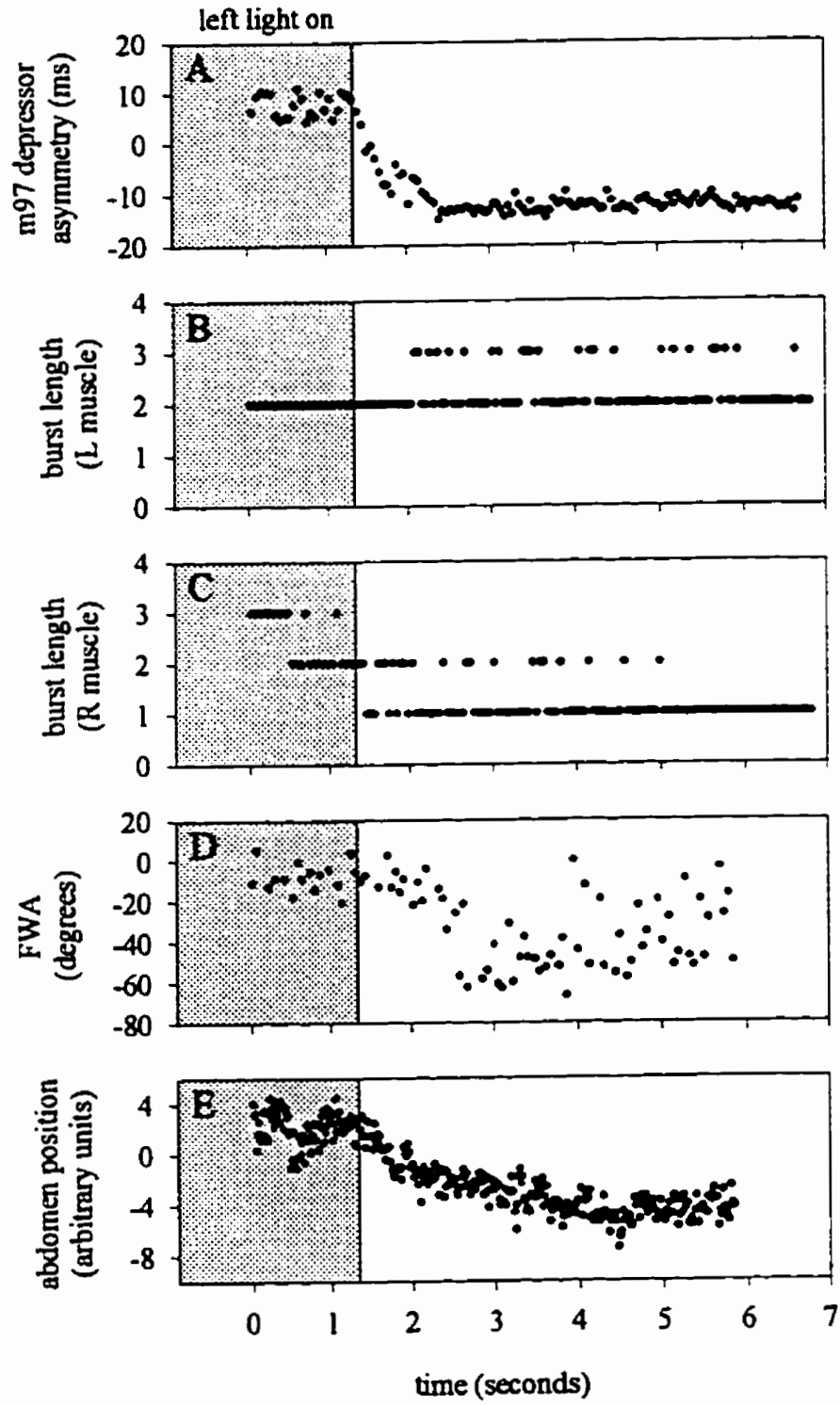
Concurrently, there was a negative FWA shift (only the FWA at the top of the downstroke is shown) and an abdomen deflection to the left. From time-aligned muscle activity, abdomen movement and wing elevations, we computed and correlated the magnitudes of their shifts. Magnitudes of shift were calculated by subtracting the pre-stimulus average from the post-stimulus average. The pre-stimulus average was based on a one-second time period at the beginning of the trace. The post-stimulus average was based on a one-second time period at a time when the abdomen appeared to have reached full deflection.

We found that when m97 asymmetry shifted positively (right muscle firing first), the right muscle fired more spikes per burst, while the contralateral muscle fired fewer spikes per burst (Fig. 9). When the asymmetry shift was negative (left muscle firing first), the spikes per burst increased in the left muscle and decreased in the right muscie. Although $\mathrm{m} 97$ is capable of firing one, two or three spikes per burst (Waldron 1967), the change in average burst length was not always a whole number. This is because often m97, instead of firing only singlets, doublets or triplets, fired a combination of singlets and doublets, or a combination of doublets and triplets.

We found significant positive correlations between the magnitudes of $\mathrm{m} 97$ asymmetry shift, abdomen deflection, and forewing asymmetry shift (Fig. 10). A positive asymmetry shift in $\mathrm{m} 97$ was significantly correlated with a positive FWA shift (Fig. 10A) and a rightward abdomen deflection (Fig. 10B). A positive FWA shift was correlated with a rightward abdomen deflection (Fig. 10C). A linear regression drawn through the data points naturally passes through the origin in all 
Fig. 9 Changes in burst length occurred with $\mathrm{m} 97$ asymmetry shifts. During a positive $\mathrm{m} 97$ asymmetry shift, when the right $\mathrm{m} 97$ was activated earlier than the left, the average burst length of the right $\mathrm{m} 97$ increased. Simultaneously, the average burst length of the left $\mathrm{m} 97$ decreased. During a negative $\mathrm{m} 97$ asymmetry shift, the left $\mathrm{m} 97$ burst length increased while the right $\mathrm{m} 97$ burst length decreased. $N=16$ 


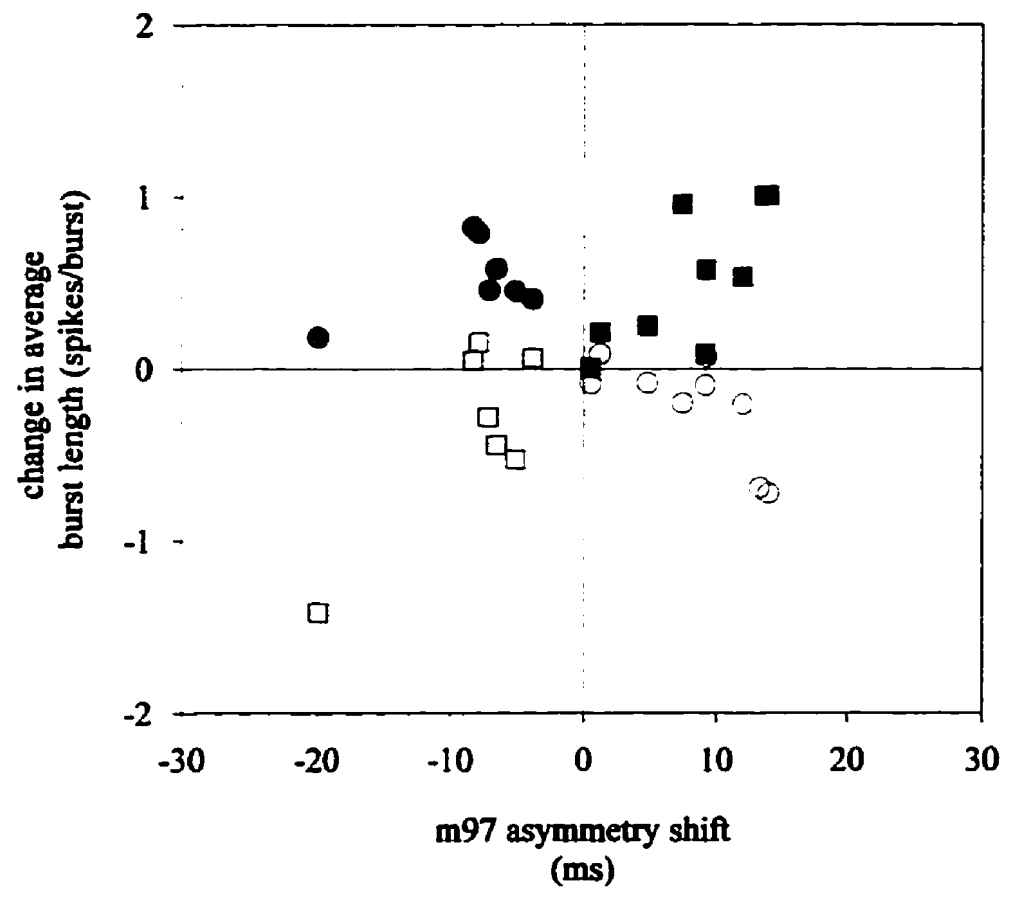

- $\mathrm{m} 97 \mathrm{~L}$, earlier activation

- $m 97 R$, earlier activation

○ $\mathbf{m} 97 \mathbf{L}$, delayed activation

$\mathbf{m} 97 \mathbf{R}$, delayed activation 
Fig. 10 Correlations between the magnitudes of $\mathrm{m} 97$ asymmetry shift, forewing asymmetry (FWA) shift, and abdomen deflection during tethered flight. $\mathbf{A}$ There was a significant positive correlation between $\mathrm{m} 97$ asymmetry shift and FWA shift. B There was a significant positive correlation between $\mathrm{m} 97$ asymmetry shift and abdomen deflection. C There was a significant positive correlation between FWA shift and abdomen deflection. 

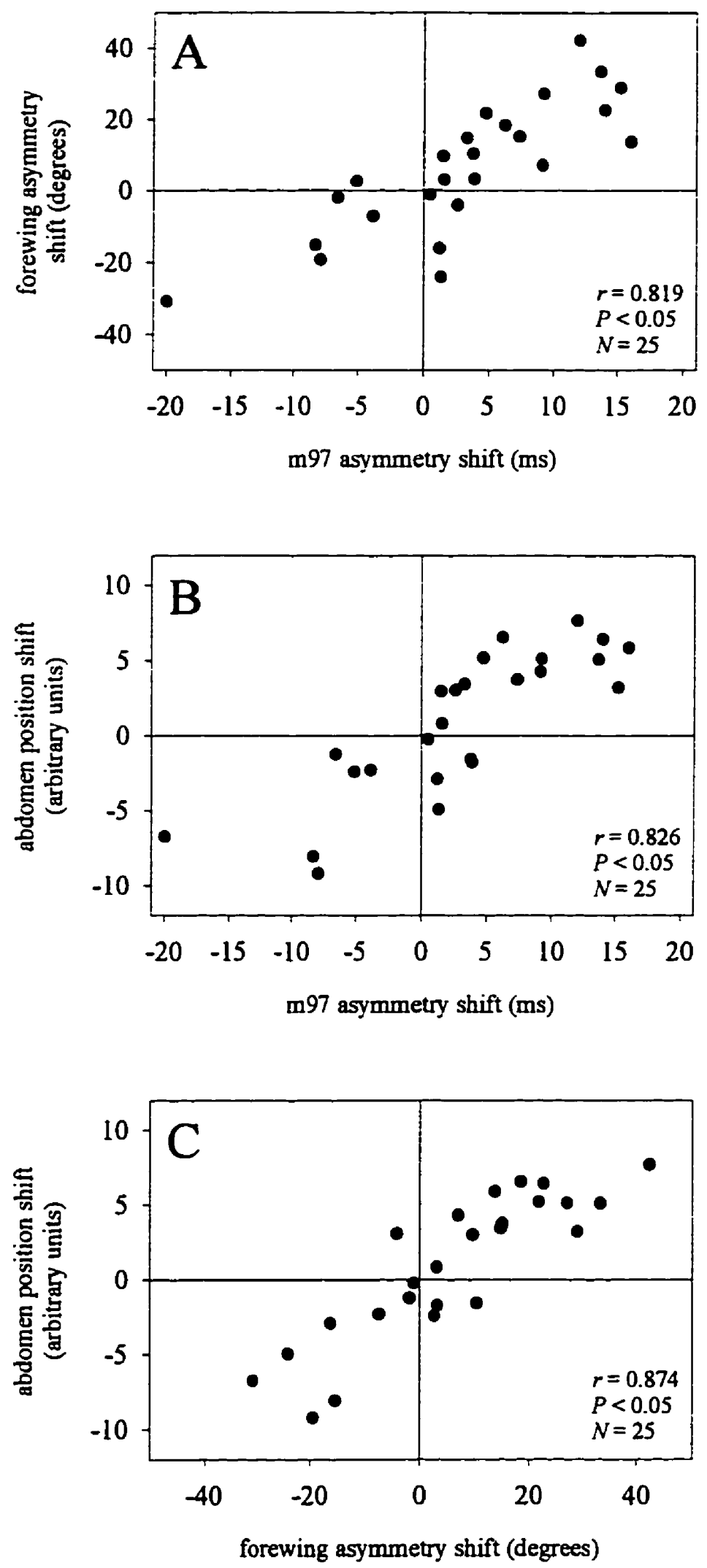
comparisons (not shown). The magnitude of the m97 depressor asymmetry shift was sometimes large: the average magnitude of shift, without regard to direction, was 7.2 $\pm 5.5 \mathrm{~ms}$. Six of 25 animals had $\mathrm{m} 97$ asymmetry shifts greater than $10 \mathrm{~ms}$, and the largest shift we observed was 19.9 ms (pre-stimulus average, $7.5 \mathrm{~ms}$; post-stimulus average, $-12.3 \mathrm{~ms})$.

\subsubsection{Activity of other downstroke muscle pairs}

Four EMG electrodes were implanted into each animal. Two of these monitored activity of left and right $\mathrm{m} 97$ muscles. The other two electrodes monitored activity from either $\mathrm{m} 85, \mathrm{~m} 98, \mathrm{~m} 99$, or $\mathrm{m} 127$ muscle pairs. We found that the downstroke muscles of the forewing, in response to thermal stimuli, showed asymmetry shifts in the same direction and often with a similar magnitude as $\mathrm{m} 97$ asymmetry shifts (Fig. 11). The m85 asymmetry shifts that occurred in response to lamp on or lamp off were similar in direction and magnitude to those that occurred in m97 (Fig. 11A top and middle traces). On the left side of the body, a negative relationship between $\mathrm{m} 97$ and $\mathrm{m} 85$ indicated that $\mathrm{m} 85$ fired later than $\mathrm{m} 97$ during the wingstroke (Fig. $11 \mathrm{~A}$ bottom trace), and on average, for four animals, m85 fired later than $\mathrm{m} 97$ by $4.4 \pm 0.5 \mathrm{~ms}$ (mean \pm s.e.m.). A small deviation is noticeable in the relationship between $\mathrm{m} 97$ and $\mathrm{m} 85$ at lamp on. This indicates that the asymmetry between left and right $\mathrm{m} 97$ muscles developed earlier or faster than the asymmetry 
Fig. 11 Simultaneous recordings from two pairs of forewing depressor muscles showed similar asymmetry shifts in response to thermal stimuli. Each panel shows data from one individual. The top two traces show asymmetry shifts from the two muscle pairs, while the bottom trace shows the timing relationship along the left side of the locust. A Simultaneous recording of $\mathrm{m} 97$ and $\mathrm{m} 85$ showed similar $\mathrm{L}-\mathrm{R}$ asymmetry shifts in both direction and magnitude during the thermal presentation (top and middle traces). There are fewer data points for $\mathrm{m} 85$ asymmetry because this muscle was not active during every wingstroke (middle trace). Muscle m97 fired before $\mathrm{m} 85$ (bottom trace) throughout most of the flight sequence (negative relationship). In this individual there was an atypical shift in the relative timing of $\mathrm{m} 97 \mathrm{~L}$ and $\mathrm{m} 85 \mathrm{~L}$. B Simultaneous recordings of $\mathrm{m} 97$ (top trace) and $\mathrm{m} 98$ (middle trace) show that these two muscle pairs shifted asymmetry in the same direction and with a similar magnitude in response to a thermal stimulus. There are fewer data points in the middle trace indicating that $\mathrm{m} 98$ was not active during every wingstroke. The relationship between $\mathrm{m} 97 \mathrm{~L}$ and $\mathrm{m} 98 \mathrm{~L}$ (bottom trace) is negative, indicating that $\mathrm{m} 98 \mathrm{~L}$ fired later than $\mathrm{m} 97 \mathrm{~L}$ during the downstroke. This relationship showed little change during the flight sequence. $C$ Muscle m97 asymmetry (top trace) and muscle m99 asymmetry (middle trace) shifted in the same direction during a thermal presentation. The relationship between $\mathrm{m} 97$ and $\mathrm{m} 99$ is negative, indicating that $\mathrm{m} 99$ was activated later in the downstroke than $\mathrm{m} 97$. A small shift in this relationship was observed at lamp off. 

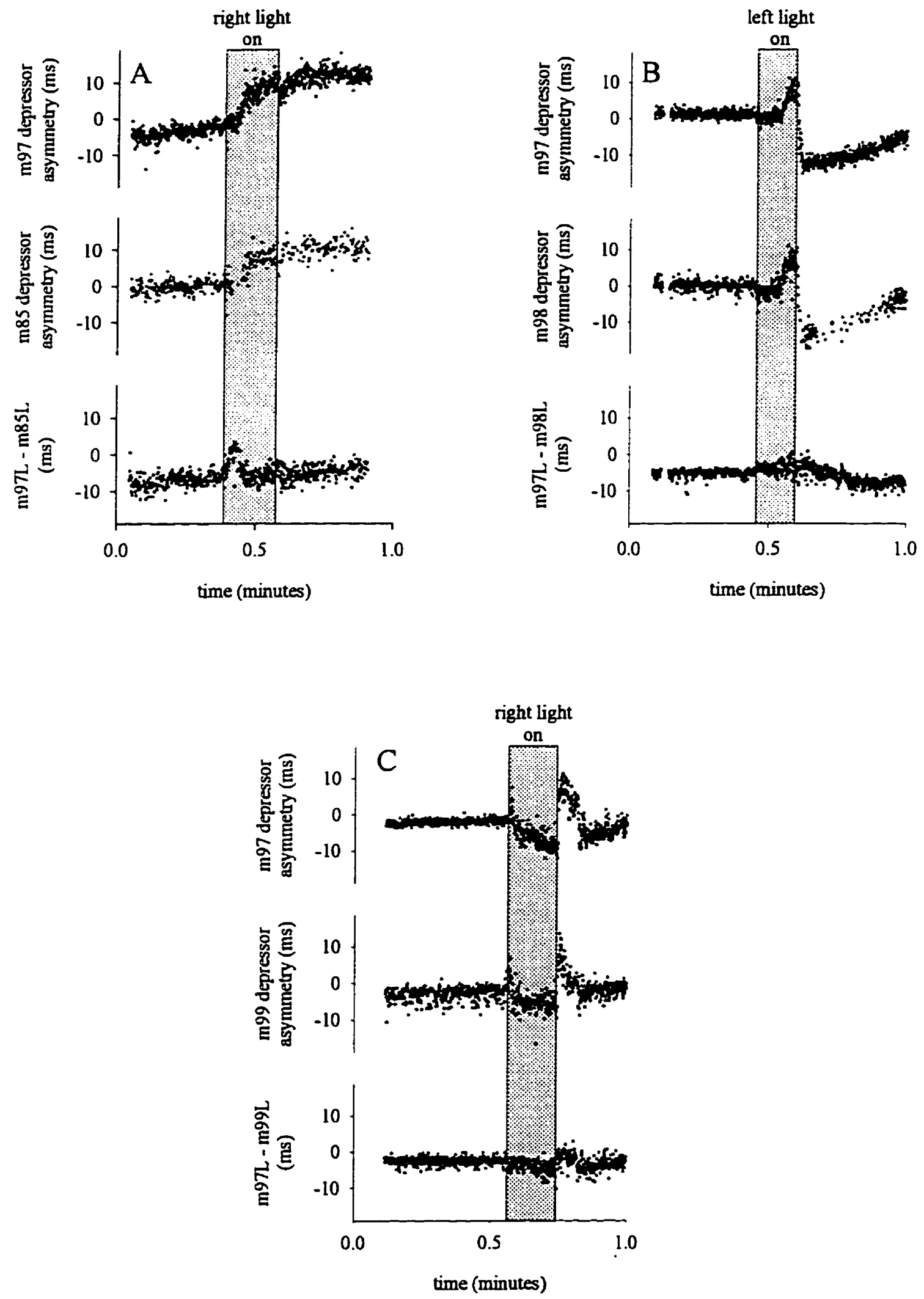
between left and right $\mathrm{m} 85$ muscles. In the other individuals from which $\mathrm{m} 97$ and m85 activity were recorded, the asymmetry shifts developed simultaneously.

Muscle $\mathrm{m} 98$ and $\mathrm{m} 97$ also underwent similar asymmetry shifts, both in direction and magnitude (Fig. 11B). A positive shift in m98 asymmetry occurred synchronously with a positive shift in $\mathrm{m} 97$ asymmetry (Fig. 11B top and middle traces). On the left side of the body, the time interval between $\mathrm{m} 97$ activity and $\mathrm{m} 98$ activity was negative, indicating that $\mathrm{m} 97$ fired before $\mathrm{m} 98$ during the downstroke (Fig. 11B bottom trace). On average, for five animals, $\mathrm{m} 98$ fired later than $\mathrm{m} 97$ by $3.7 \pm 0.2 \mathrm{~ms}$ (mean \pm s.e.m.).

Muscle $\mathrm{m} 97$ and $\mathrm{m} 99$ also show similarities in asymmetry shift direction (Fig. 11C). At lamp on, m97 depressor asymmetry gradually developed, while at lamp off, a large and abrupt asymmetry shift occurred. Asymmetry shifts in $\mathrm{m} 99$ followed a similar trend. The relationship between $\mathrm{m} 97$ and $\mathrm{m} 99$ on the left side of the body was negative, indicating that $\mathrm{m} 97$ fired earlier than $\mathrm{m} 99$ during the downstroke. A small shift in this relationship was observed at lamp off (Fig. $11 \mathrm{C}$ bottom trace).

In a correlation analysis, we show significant positive relationships between m97 and m85 asymmetry shifts (Fig. 12A), m97 and m98 asymmetry shifts (Fig. 12B) and m97 and m99 asymmetry shifts (Fig. 12C). This means that for an asymmetry shift in $\mathrm{m} 97$, there is a corresponding asymmetry shift in $\mathrm{m} 98, \mathrm{~m} 99$, and m85. From the slope of a Model II regression analysis (principal axis slope) and the equation for a t-test, we determined whether the slope of the principal axis for each correlation was significantly different from a slope of 1 which is shown by a dotted 
Fig. 12 There were significant positive correlations between asymmetry shifts of pairs of forewing depressor muscles. The dotted red line indicates a slope of 1 . A There was a significant positive correlation between asymmetry shifts in $\mathrm{m} 97$ and m85. A Model II regression fit to the data was not significantly different from a slope of 1 (see text). B There was a significant positive correlation between asymmetry shifts in $\mathrm{m} 97$ and $\mathrm{m} 98$. A model II regression fit to the data was not significantly different from a slope of 1. C There was a significant positive relationship between asymmetry shifts in $\mathrm{m} 97$ and $\mathrm{m} 99$. A Model II regression fit to the data was significantly different from a slope of 1 . 

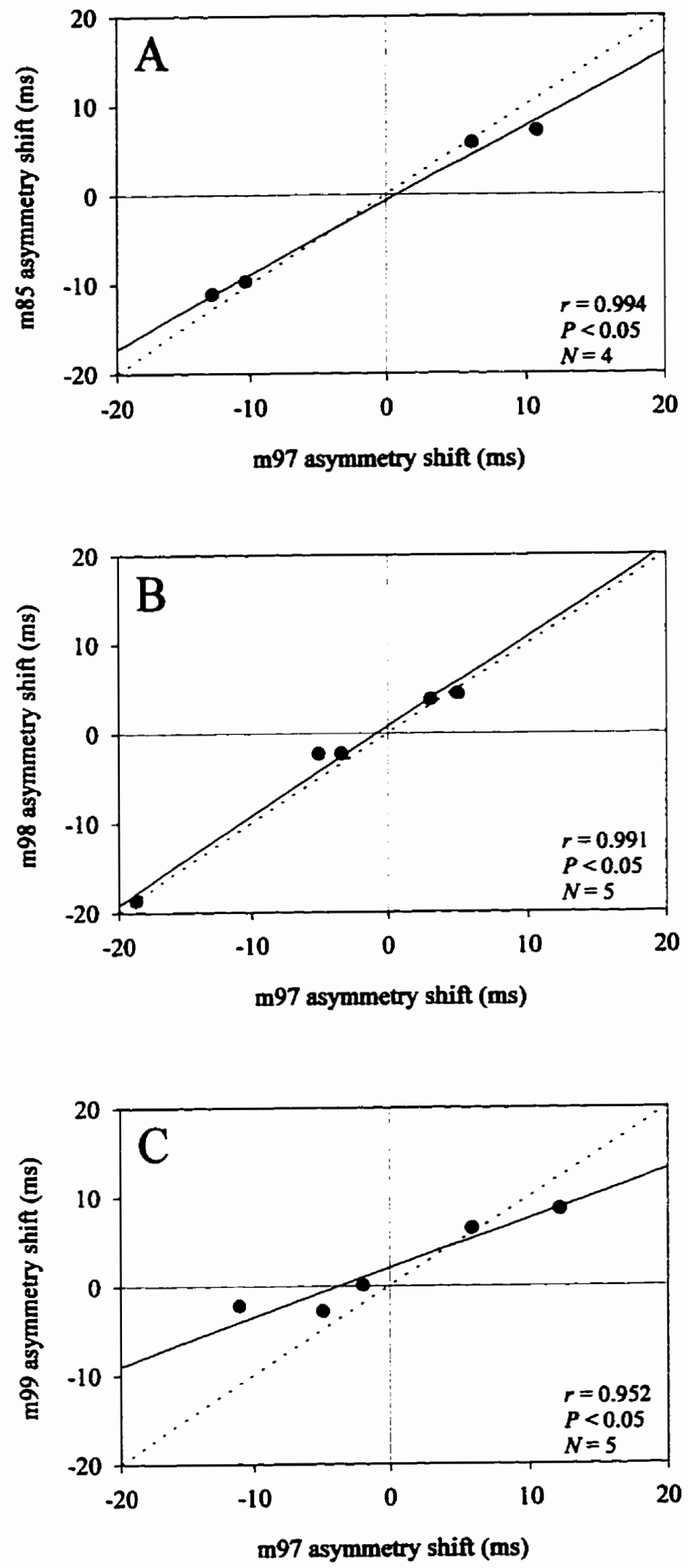
red line. The slope of the principal axis in the correlation between $\mathrm{m} 97$ and $\mathrm{m} 85$

was not significantly different from a slope of 1 ( $t$-test, $t=3.15, N=4, P>0.05$ ). The slope of the principal axis in the correlation between $\mathrm{m} 97$ and 98 was also not significantly different from a slope of 1 ( $t$-test, $t=0.006, N=5, P>0.05$ ). The slope of the principal axis in the correlation between $\mathrm{m} 97$ and $\mathrm{m} 99$ was significantly different from a slope of 1 ( $t$-test, $t=7.9, N=5, P<0.05$ ) indicating that the magnitudes of shift of $\mathrm{m} 97$ asymmetry and $\mathrm{m} 99$ asymmetry are not the same. Muscles $\mathrm{m} 97$ and $\mathrm{ml} 27$ shifted in opposite directions during a thermal presentation (Fig. 13A top and middle traces). The magnitude of $\mathrm{m} 127$ shift that occurred in this animal was similar to the shift in $\mathrm{m} 97$, but this is atypical. Typically, the size of m 127 shifts were smaller than the shifts observed in m97. Based on the slope calculated from a Model II regression, the shifts in $\mathrm{m} 127$ were only 0.4 times the size of $\mathrm{m} 97$ asymmetry shifts. The relationship between $\mathrm{m} 127$ and m97 on the left side of the body varied during the flight sequence (bottom trace) although mI27 usually fired first (positive relationship). A correlation analysis of m97 asymmetry shifts and m127 asymmetry shifts for 20 animals was negative (Fig. 13B). This indicates that a positive m97 asymmetry shift is coincident with a negative $\mathrm{ml} 27$ asymmetry shift during a steering response to radiant heat. 
Fig. 13 Simultaneous recordings from pairs of forewing (m97) and hindwing (m127) depressor muscles showed opposite asymmetry shifts in response to thermal presentations. A Muscle $\mathrm{m} 97$ asymmetry (top trace) and $\mathrm{ml} 27$ asymmetry (middle trace), recorded from an individual locust, showed that $\mathrm{ml} 27$ shifted in the opposite direction from m97 and with a smaller magnitude during a thermal stimulus. The relationship between $\mathrm{m} 97 \mathrm{~L}$ and $\mathrm{m} 127 \mathrm{~L}$ (bottom trace) was variable. Note that following the thermal presentation, the locust twice stopped and restarted flight. Although the animal restarted without depressor asymmetry, it was quickly reestablished within the first few wingbeats. B Summarized data from twenty animals. There was a significant negative relationship between $\mathrm{m} 97$ and $\mathrm{m} 127$ asymmetry shift during thermal presentations. 

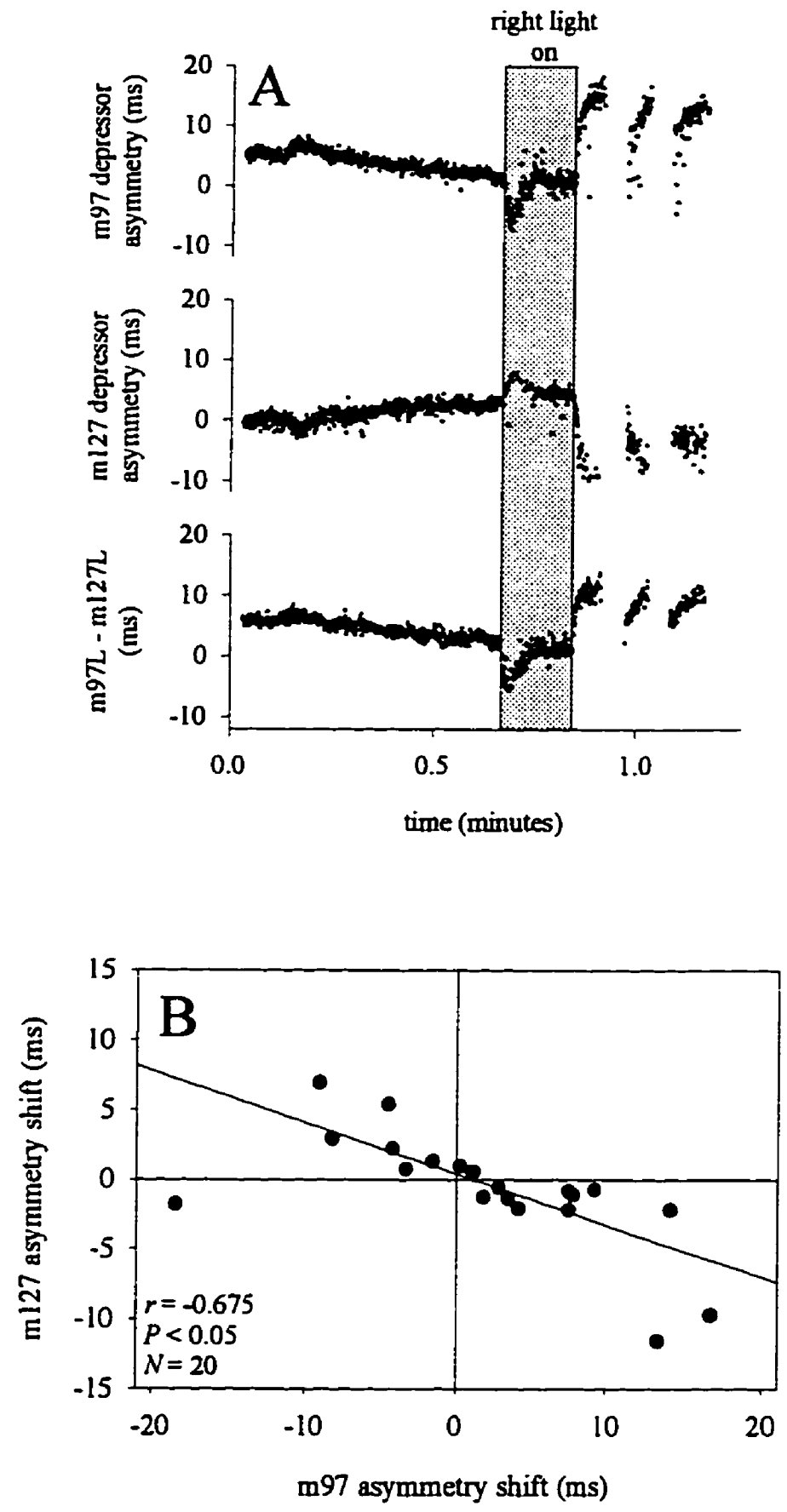


\subsection{Discussion}

\subsubsection{Behaviour}

During flight, it is critical that locusts respond quickly and appropriately to external stimuli. Dangerous stimuli indicating a predator or an approaching obstacle must be avoided while other stimuli, such as a potential mate or a food source, are attractive and may be approached.

A previous study of steering behaviour in response to radiant heat found that locusts perform avoidance manoeuvres (Robertson et al. 1996). This behaviour implies that the stimulus is associated with danger. The present experiment produced an interesting result in that the attempted steering responses were variable. Although it is true that very few animals attempted a turn toward an illuminated heat lamp, some animals attempted to turn away from it, while others only responded at lamp off by attempting to turn towards it (some do both). From these behaviours, it seems reasonable to conclude that the locust is attempting to thermoregulate by steering towards a preferred temperature. Thus, when a locust does not steer away from lamp on, but turns towards the direction of the source immediately following the stimulus, this indicates that the locust prefers the warmer temperature. When a locust attempts a turn away from the heat lamp when it is on, and returns to straight flight when it is off, this indicates that the locust is comfortable at room temperature, and avoids the risk of overheating by avoiding the heat lamp. 
It may be argued that the animals in these experiments are not responding to radiant heat at all, but are instead responding to the aerodynamic consequences of changing air densities. Warmer air, caused by an illuminated heat lamp, would decrease the air density on one side of the locust. Knowing that, at least for hovering flight, aerodynamic force production depends on air density (Ellington 1984), then it can be assumed that, on the heated side of the body, there would be an alteration in wing kinematics to compensate for density differences. Although this may have some effect on steering behaviour, we do not feel that it is the main factor at play in our experiments for two reasons. Firstly, the relatively cool air currents generated by the wind tunnel should destroy any air density differences created by the heat lamp. Secondly, if air density differences did have an effect, then we would expect that the responses to lamp on and lamp off would be equal in magnitude and opposite in direction. This is not consistent with our data. We are confident that the responses we observe are a direct result of the radiant heat. Regardless of the motivation for steering, the behaviour in response to radiant heat includes FWA, abdomen deflection, and motor pattern modification which will now be discussed.

\subsubsection{Forewing asymmetry and abdomen position}

During intentional steering manoeuvres, we observed abdomen deflections as well as forewing asymmetries in which the forewing ipsilateral to the turn was more 
depressed than the contralateral wing during the downstroke. In a correlation analysis, we found that the magnitudes of shift of these two variables were significantly and positively correlated with one another, as well as with corresponding m97 asymmetry shifts.

Certainly, abdomen deflection has long been a correlate of steering direction. Camhi (1970) described, for both correctional and intentional steering, that the abdomen deflects into the direction of the turn. Most researchers of locust flight steering agree that abdomen deflection is important in steering by increasing drag on the side of the intended turn.

Fewer researchers agree on the idea that forewing asymmetries in elevation play a role in steering manoeuvres. Some researchers have described phase shifts in forewing depression during correctional manoeuvres (Baker 1979a; Thüring 1986; Zarnack 1988; Waldmann and Zarnack 1988) but often claim that their resultant flight forces are not important for steering. However, intentional steering studies describe forewing asymmetries on a larger scale (Robertson and Reye 1992; Robertson and Johnson 1993; Dawson et al. 1997; Robertson et al. 1996), in which the forewing ipsilateral to the turn can sometimes be more depressed than the ipsilateral hindwing during the downstroke. Although the aerodynamic effect of these asymmetries remains to be determined, their predicted effects are explained below.

Although the correlations between m97 asymmetry shifts, abdomen deflection and forewing asymmetry shifts are very tight, it is difficult to ignore those data points that indicate large negative FWA shifts but small positive $\mathrm{m} 97$ asymmetry shifts (Fig. 
I0A), or a positive m97 asymmetry shift with an abdomen deflection to the left (Fig. 10B). Camhi (1970) also found considerable scatter on his plots of abdomen position during corrective steering, yet offers no explanation for this.

We believe that this scatter is an artefact of the technical limitations of our experiments. The first limitation is the rigid tether. Tethering the animal can affect its flight. The animal does not generate $100 \%$ lift, exteroceptive input (eg. direction of wind) is abolished during steering behaviours, and motor pattern biases may occur (Möhl 1985).

A second limitation is our videotaping procedure. A filming speed of 60 frames/second only captures the wings in a downstroke position on approximately every third frame. Even fewer frames captured the wings at the top of the downstroke.

Despite these limitations, we are confident that the correlations of these behaviours are real for the following reasons. Firstly, we saw coordinated steering behaviour involving the wings, muscles and abdomen. Secondly, these steering behaviours were coincident with the onset or end of the thermal presentation. Thirdly, the animals steered both to the left and the right, suggesting that tethering biases, if present, were minimal. 


\subsubsection{Burst length}

During steering manoeuvres, we found relationships between the timing activity of $\mathrm{m} 97$ and the number of spikes it fired per burst. Generally, when $\mathrm{m} 97$ advanced its timing in the wingbeat cycle, its burst length increased. A similar trend has been found by Baker (1979b), Dugard (1967), and Waldron (1967). Sometimes, the $\mathrm{m} 97$ that was delayed in its timing fired fewer spikes per burst, and in this way, the burst length of m97 on opposite sides of the body experienced a "push-pull" relationship. However, the $\mathrm{m} 97$ burst length on the outside of the turn did not always decrease. We offer two explanations for why the muscle on the inside of the intended turn always increased its burst length while the muscle on the outside decreased its burst length only sometimes. 1) During stimulus presentation, the wingbeat frequency increases, which is associated with increased burst length (Wilson and Weis-Fogh 1962). Thus, on the inside of the turn, an increased burst length due to m97 timing changes was compounded by the increase due to WBF. On the outside of the turn, however, increases in burst length due to WBF would cancel any decrease due to timing delay. 2) During straight flight, the $\mathrm{m} 97$ muscles often fire singlets. During a steering manoeuvre, the $\mathrm{m} 97$ on the inside of the turn increases its burst length, but on the outside of the turn, unless it stops firing completely, the muscle activity cannot decrease. 


\subsubsection{Wingbeat frequency}

During steering manoeuvres, significant increases in wingbeat frequency were recorded. Since it is known that temperature influences WBF in locusts (Foster and Robertson 1992), then it might be argued that the change in WBF is due to nonspecific effects of an increase in thoracic temperature rather than being a component of the manoeuvre. For two reasons, we feel that this is unlikely. Firstly, the increase in WBF is brief relative to the length of the thermal presentation. Shortly after the stimulus onset, it returns to pre-stimulus values, even though the temperature is rising. Secondly, this increase in frequency occurs when temperatures increase at lamp on and when temperatures decrease at lamp off. Based on these observations, we propose that the increase in WBF is part of a startle response associated with relatively abrupt changes in radiant heat.

\subsubsection{Motor patterns and proposed model}

During thermal presentations, we observed large asymmetry shifts in muscle activity in response to both lamp on and lamp off. Although we only recorded from two muscle pairs (four electrodes) at once, we can, based on the relationships between m97 and the other recorded muscles, construct a prediction of how all the muscles interact during a thermal steering manoeuvre (Fig. 14). Before the stimulus is 
Fig. 14 Schematic diagram of motor pattern modulation of depressor muscles during a thermal presentation. Forewing muscles $\mathrm{m} 97, \mathrm{~m} 98, \mathrm{~m} 99$, and $\mathrm{m} 85$ were included in this study, along with hindwing muscle $\mathrm{m} 127$. A In the absence of a stimulus, during straight flight, homologous muscle pairs fire synchronously. Muscle $\mathrm{ml} 27$ of the hindwing is activated before the muscles of the forewing. B When attempting to steer, the wingbeat frequency increases (shorter period). Here we show an $\mathrm{m} 97$ asymmetry shift of $10 \mathrm{~ms}$. In both wings, the relationship between $\mathrm{m} 97, \mathrm{~m} 98$ and m85 remains constant. The sequence of firing remains constant between $\mathrm{m} 97, \mathrm{~m} 98$, $\mathrm{m} 99$ and $\mathrm{m} 85$. Although not included here, there are also changes in m97 burst length during steering (see results). 
A

Before Stimulus

m85

m127
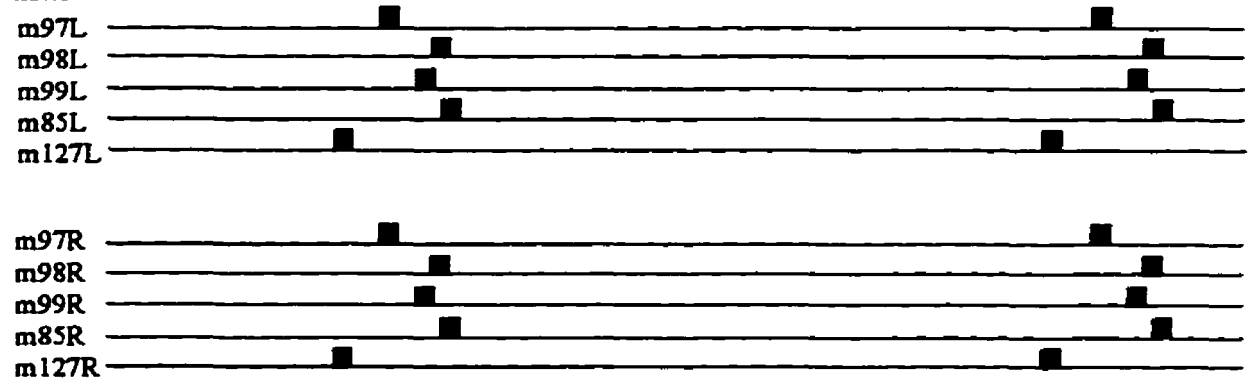

B

After Stimulus

m97L

m98L

m99L

m85L

m127L
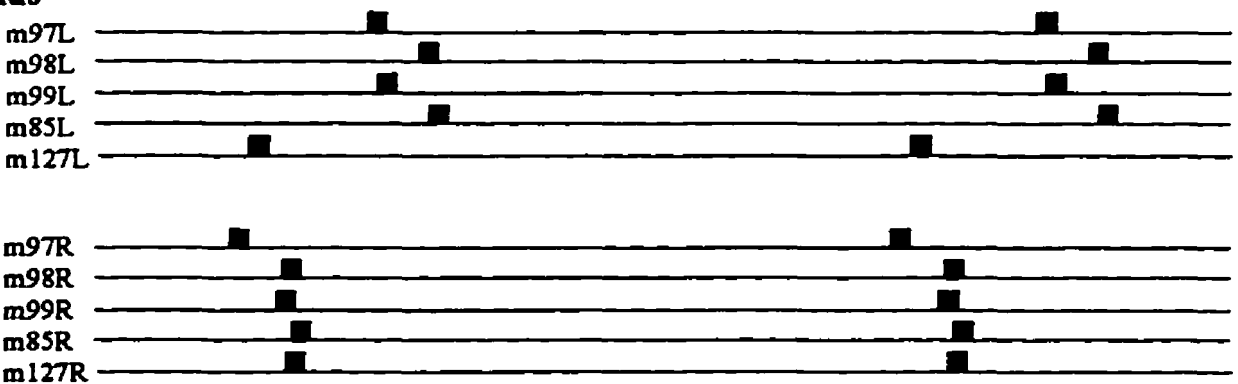

m127R

0

10

20

30

40

50

60

70

80

time (ms) 
presented, during perfectly straight flight, all contralateral muscles fire synchronously. Hindwing first basalars (m127) are activated first. This is to be expected since the hindwings lead the forewings during straight flight (Wilson and Weis-Fogh 1962). Approximately $3.5 \mathrm{~ms}$ later, the forewing first basalars (m97) fire. Following $\mathrm{m} 97$, in sequence, are the activity of $\mathrm{m} 99, \mathrm{~m} 98$, and $\mathrm{m} 85$. Every $50 \mathrm{~ms}$, at a wingbeat frequency of $20 \mathrm{~Hz}$, this pattern of activity is repeated. The sequence of muscle firing for $\mathrm{m} 97, \mathrm{~m} 98, \mathrm{~m} 99$, and $\mathrm{ml} 27$ is similar to that found by Wilson and Weis-Fogh (1962, refer to Fig. 4) and Möhl (1985).

In Fig. 14B, we show the modification of muscle activity in response to a thermal stimulus. The muscle activity is based on the positive $\mathrm{m} 97$ asymmetry shift of $10 \mathrm{~ms}$, which corresponds to a right-hand turn. We chose a $10 \mathrm{~ms}$ shift because it is within the range of observed responses, and it generates a model in which muscle shifting is more obvious. Across the body, the right $\mathrm{m} 97$ is firing $10 \mathrm{~ms}$ before the left m97. The wingbeat frequency increases during a stimulus, and in Fig. 14B is shown to be $21 \mathrm{~Hz}$. The hindwing first basalars $(\mathrm{m} 127)$ undergo an opposite shift to the forewing first basalars (m97). This occurrence is supported by Thüring (1986) and Möhl (1985). While in the $\mathrm{m} 97$ pair the right muscle fires first, in the $\mathrm{m} 127$ pair the left muscle fires first. Muscle $\mathrm{m} 127 \mathrm{~L}$ fires approximately $8.5 \mathrm{~ms}$ earlier than $\mathrm{m} 97 \mathrm{~L}$. On the right side of the body $\mathrm{ml27}$ is firing in time with some of the forewing muscles, and fires about $4 \mathrm{~ms}$ after m97.

In the forewings, for both the left and right sides of the body, the timing relationship between $\mathrm{m} 97, \mathrm{~m} 98$ and $\mathrm{m} 85$ maintain their pre-stimulus relationship. In 
other words, in the case of Fig. 14B, these muscles on the right side of the body all fire $10 \mathrm{~ms}$ before their corresponding contralateral muscles. Muscle m99, however, although maintaining its place in the sequence of forewing depressor activity, is asymmetrically phase-shifted in its timing. On the left side of the body, $\mathrm{m} 97$ and m99 fire almost synchronously, with $\mathrm{m} 99$ firing only about $0.5 \mathrm{~ms}$ after $\mathrm{m} 97$. On the right side of the body, $\mathrm{m} 99$ fires more than $3 \mathrm{~ms}$ after $\mathrm{m} 97$.

The phase difference in timing in $\mathrm{m} 99$ across the body could affect the angle of attack during steering. Wilson and Weis-Fogh (1962) state that the changes in angle of attack of the forewings is due to changes in the phase of activity of the subalar muscle. Muscle $\mathrm{m} 99$ (supinator) controls the angle of attack by counteracting the effects of $\mathrm{m} 97$ (pronator). In our model, the synchronous firing of $\mathrm{m} 97$ and $\mathrm{m} 99$ on the left side of the body would lead to decreased pronation and an increased angle of attack. On the right side of the body, the long latency between $\mathrm{m} 97$ and $\mathrm{m} 99$ would cause increased pronation and a decreased angle of attack. Since an increased angle of attack is associated with increased lift, the right hand side of the body (inside of the turn) would generate less lift, and result in a banked turn to the right. This prediction of wing kinematics is consistent with the observations made during both correctional and intentional steering (for review see Kammer 1985; Rowell 1988).

Muscle $\mathrm{m} 85$ is different from the other muscles studied in this report because it is not a direct depressor muscle. Instead, evidence suggests that it exerts fine control over the degree of pronation of the forewings by decreasing pronation during the downstroke (Elson and Pflüger 1986; Wolf 1990). It may act by increasing its 
activity (burst length) or recruiting a second motor unit. Our data cannot support or refute the observations of Elson and Pflüger (1986) or Wolf (1990) because we did not analyse number of spikes per burst or analyse the traces for motor unit recruitment. We can predict, however, that if $\mathrm{m} 85$ is taking part in counteracting pronation during the downstroke, that it acts together with $\mathrm{m} 99$.

\subsubsection{Aerodynamic effect of forewing asymmetry}

During straight and steady flight, the forewings depress symmetrically, and, assuming that each forewing has an equal aerodynamic effect, the resultant lift vector will lie in a plane that bisects the angle between the forewings. In other words, lift is straight upwards during straight flight (Dawson et al. 1997).

During forewing asymmetry, the lift vector still bisects the angle between the two forewings, but now the forewing ipsilateral to the intended turn is more depressed during the downstroke than the opposite forewing. The lift vector is thus inclined to the side of the intended turn, resulting in a roll manoeuvre. Because roll and yaw are interrelated (Baker 1979a) this laterally displaced lift vector will result in a banked turn in the direction of the more depressed forewing.

Bulk shifts in forewing muscle activity offer an explanation for FWA. During a right turn, in which the right forewing is more depressed than the left forewing, the right forewing depressor muscles are all advanced in their timing. An earlier 
contraction would lead to an earlier stroke reversal, and thus phase-shifting of wing depression. This explanation is additionally convincing since the magnitude of the bulk shift is strongly correlated with the magnitude of FWA shift. In the case of a right turn, the earlier the advance of the bulk shift, the greater the magnitude of FWA.

Many researchers maintain that pronation and supination are the key elements generating the aerodynamic forces for turning (Baker 1979a; Zamack 1988; Waldmann and Zarnack 1988). They have found that on the side of the intended turn, increased pronation (decreased angle of attack) would decrease lift generated on that side. On the side contralateral to the intended turn, decreased pronation (increased angle of attack) would increase lift of that side. This differential lift would generate a steering manoeuvre in the same direction as the forewing asymmetry. We did not, in our experiments, investigate the occurrence of pronation or supination, but we believe that these changes probably occur in addition to FWA, and that their aerodynamic forces augment the effects of FWA. Based on our predicted model, it is likely that pronation and supination do occur based on the phase-shifting of $\mathrm{m} 99$ on left and right sides.

Hindwing asymmetry was not analysed in our experiments. However, the direction of the hindwing first basalars asymmetry is opposite to that of the forewing first basalar asymmetry. If this is any indication of wing elevation asymmetry, then we would expect that the hindwings would generate elevation asymmetry opposite to FWA. This relationship has been suggested by Möhl (1985) and Thüring (1986) and 
the aerodynamic consequences would likely involve the aerodynamic interplay between the ipsilateral forewing and hindwing (Waldmann and Zarnack 1988).

However, recent work (Robertson et al. 1996) in a study of hindwing kinematics, describes the hindwings beating symmetrically during steering manoeuvres. It is possible that $\mathrm{ml} 27$ asymmetry shifts are solely a reflection of hindwing pronation, and that bulk shifts in hindwing depressor activity do not occur. Further analysis would be required to distinguish between these two possibilities. 


\section{CHAPTER THREE}

\section{GENERAL DISCUSSION}

In this study I have shown that asymmetries in activity of m97 on left and right sides are strongly and positively correlated with forewing asymmetries in elevation during intentional steering in response to thermal stimuli. Asymmetry shifts were also observed in $\mathrm{m} 85$ and $\mathrm{m} 98$ that were equal in magnitude and direction to those in $\mathrm{m} 97$. Muscle $\mathrm{m} 99$ shifted in the same direction as $\mathrm{m} 97$ but with a smaller magnitude. I propose that bulk shifts of the timing of depressor motor neuron activity observed during intentional steering underlie forewing asymmetries and thus represent an important motor strategy for avoidance during flight.

Bulk shifts, as well as phase shifts in stroke reversal timing, have now been described for both intentional steering and correctional steering (Zarnack and Möhl 1977; Thüring 1986). This means that the motor output for correctional and intentional steering are similar, if different in degree. This result is reasonable in consideration of the locust musculature. Because there are only 3 direct depressor muscles, and because each also plays a role in adjusting the angle of attack, then a phase shift in only one muscle without a phase shift in the other two would result in a modified angle of attack without a change in FWA. However, a similar shift in all 3 direct depressor muscles would advance the timing of the stroke reversal on one side of the body, and thus generate a FWA. 
However, it could not have been assumed that the motor patterns of intentional and correctional steering would be qualitatively identical, because many other aspects of these types of steering are different. Abdomen deflections occur between different body segments (Camhi 1970) and the head moves in different directions (Robert and Rowell 1992). In order to ultimately determine how the sensory information is integrated into the flight circuitry, it was first necessary to firmly establish the motor pattern of intentional steering.

The study of sensorimotor integration can be approached from two directions. One approach is at the level from interneurons to motor output. How is their activity altered during thermal presentations? Answering this question is feasible because the locust flight system is well-characterized, and there are many established techniques. The motor patterns during straight flight have already been determined (Wilson and Weis-Fogh 1962) and it is possible to record intracellularly from flight interneurons (Robertson and Pearson 1982). Additionally, the activity of flight interneurons can be recorded during intact tethered flight (Wolf and Pearson 1987). These preparations will allow us to determine how the pattern of interneuron activity is modified during thermal presentations in almost intact flight. Additionally, it would be possible using neurophysiological techniques, to experimentally alter the activity of motor neurons or interneurons to determine how their activity specifically affects wing kinematics. Determining how each individual muscle controls wing movements is a necessary study because so far only correlative relationships have been established between muscle activity and wing movements. No causal relationships have been reported. 
Another approach to studying sensorimotor integration is from the sensory structure to the central flight circuitry. Since the steering manoeuvres we observed were not due to general temperature effects, there must be radiant heat detectors capable of detecting differences across the body. From recent work it has been shown that the eyes, ocelli, and antennal flagellae do not mediate the response (Robertson et al. 1996). We have confirmed here that the eyes and ocelli do not function as thermoreceptors since they were covered with ceramic paint. Additionally, sense organs on the legs cannot mediate the response, since they were removed prior to the experiment.

Infrared detectors have been found in other poikilothermic animals. The Buprestid beetle of the genus Melanophila has paired thoracic pit organs that detect infrared radiation from recent forest fires where they lay their eggs in freshly burnt wood (Schmitz et al. 1997). The crotalid snake has facial pits that are very sensitive to infrared radiation so can locate prey both in the dark and underground (Bullock and Diecke 1956).

It is possible that locusts also have infrared organs. Slifer (1951) first described paired structures on the head by the antennae, on the thorax, and on the abdomen. These areas were cuticular in structure, but differed from surrounding cuticle in that they lacked a cement layer. By performing ablation experiments on the structures on the head (antennal crescents) she found that the locust modified its behaviour in how it oriented to the heat and proposed that the antennal crescents were thermoreceptors, whose lateral placement made them ideal for detecting temperature 
changes across the body.

Dunham (1962) performed infrared absorptivity experiments on antennal crescents and found that they absorbed more infrared than ordinary cuticle, which supported Slifer's prediction of their role as thermoreceptors.

However, Makings (1964) found in ablation studies that the destruction of antennal crescents does not affect orientation behaviour. A later study (Makings 1987) suggested that the crescents along with similar structures along the thorax and abdomen were, in fact, regions of high evaporative cooling that rid excess heat from critical and vulnerable organs.

The relative complexity of the thermal orienting behaviour described here and the different physical conditions that prevail during flight might warrant a further attempt to test the hypothesis that the antennal crescents function as infrared receptors. At the very least it is important to discover the sense organs that do mediate the behaviour. Then the control of this interesting behaviour can be investigated from the sensory discharge at the organ to the motor discharge which produces the wing kinematics for steering. 


\section{LTERATURE CITED}

Arbas EA (1986) Control of hindlimb posture by wind-sensitive hairs and antennae during locust flight. J Comp Physiol A 159: 849-857

Baader A (1990) The posture of the abdomen during locust flight: regulation by steering and ventilatory intemeurones. J Exp Biol 151: 109-131

Baker PS (1979a) The wing movements of flying locusts during steering behaviour. J Comp Physiol 131: 49-58

Baker PS (1979b) The role of forewing muscles in the control of direction in flying locusts. J Comp Physiol 131: 59-66

Bullock TH, Diecke FPJ (1956) Properties of an infra-red receptor. J Physiol 134: 47 87

Camhi JM (1970) Yaw-correcting postural changes in locusts. J Exp Biol 52: 519-531

Chapman RF (1976) A biology of locusts. Edward Amold Ltd., London 
Chappell MA (1983) Thermal limitations to escape responses in desert grasshoppers. Anim Behav 31: 1088-1093

Chappell MA, Whitman DW (1990) Grasshopper thermoregulation. In: Chapman RF, Joern A (eds) Biology of Grasshoppers. John Wiley and Sons, New York Chichester Brisbane Toronto Singapore, pp. 143-172

Cooter RJ, Baker PS (1977) Weis-Fogh clap and fling mechanism in Locusta. Nature 269: $53-54$

Dawson JW, Dawson-Scully K, Robert D, Robertson RM (1997) Forewing asymmetries during auditory avoidance in flying locusts. J Exp Biol (in press)

Dugard JJ (1967) Directional change in flying locusts. J Insect Physiol 13: 1055-1063

Dunham J (1962) Infrared transmission of fenestrae and ordinary cuticle of the grasshopper. Physiol Zool 35: 297-303

Ellington CP (1984) The aerodynamics of hovering insect flight. VI. Lift and power requirements. Philos Trans R Soc Lond B 305: 145-181 
Ellington CP, van den Berg C, Willmott AP, Thomas ARL (1996) Leading-edge vortices in insect flight. Nature 384: $626-630$

Elson R, Pflüger H-J (1986) The activity of a steering muscle in flying locusts. J Exp Biol 120: 421-441

Evans HE (1984) Insect biology. Addison-Wesley Publishing Company, Don Mills

Foster JA, Robertson RM (1992) Temperature dependency of wingbeat frequency in intact and deafferented locusts. J Exp Biol 162: 295-312

Jensen M (1956) Biology and physics of locust flight. III. The aerodynamics of locust flight. Phil Trans R Soc Lond B 239: $511-552$

Kammer AE (1985) Flying. In: Kerkut GA, Gilbert LI (eds.) Comprehensive Insect Physiology, Biochemistry and Pharmacology Vol 5. Pergamon Press, New York, pp.491-552

Makings P (1964) Slifer's patches and the thermal sense in Acrididae (Orthoptera). J Exp Biol 41: 473-497 
Makings P (1987) Survival value of Slifer's patches for locusts at high temperature. J Insect Physiol 33: 815-822

Möhl B (1985) The role of proprioception in locust flight control I. Asymmetry and coupling within the time pattern of motor units. J Comp Physiol A 156: 93-101

Pearson KG (1993) Common principles of motor control in vertebrates and invertebrates. Annu Rev Neurosci 16: 265-297

Rainey RC (1974) Biometeorology and insect flight: some aspects of energy exchange. Ann Rev Entomol 19: 407-439

Robert D (1989) The auditory behaviour of flying locusts. J Exp Biol 147: 279-301

Robert D, Rowell CHF (1992) Locust flight steering II. Acoustic avoidance manoeuvres and associated head movements, compared with correctional steering. $\mathrm{J}$ Comp Physiol A 171: 53-62

Robertson RM, Johnson AG (1992) Collision avoidance of flying locusts: steering torques and behaviour. J Exp Biol 183: 35-60 
Robertson RM, Kuhnert CT, Dawson JW (1996) Thermal avoidance during flight in the locust Locusta migratoria. J Exp Biol 199: 1383-1393

Robertson RM, Pearson KG (1982) A preparation for the intracellular analysis of neuronal activity during flight in the locust. J Comp Physiol 146: 311-320

Robertson RM, Reye DN (1992) Wing movements associated with collisionavoidance manoeuvres during flight in the locust Locusta migratoria. J Exp Biol 163 : 231-258

Rowell CHF (1988) Mechanisms of flight steering in locusts. Experientia 44: 389-395

Schmitz H, Bleckmann H, Mürst M (1997) Infrared detection in a beetle. Nature 386: $773-774$

Slifer EH (1951) Some unusual structures in Locusta migratoria migratorioides and their possible function as thermoreceptors. Proc Roy Soc Lond B 138: 414-437

Snodgrass RE (1929) The thoracic mechanism of a grasshopper and its antecedents. Smithson misc Collns 82: 1-111 
Taylor CP (1981) Contribution of compound eyes and ocelli to steering of locusts in flight I: Behavioural analysis. J Exp Biol 93: 1-18

Thüring DA (1986) Variability of motor output during flight steering in locusts. J Comp Physiol A 158: 653-664

Uvarov B (1966) Grasshoppers and locusts: A handbook of general Acridology Volume I. Cambridge University Press, Cambridge

Uvarov B (1977) Grasshoppers and locusts: A handbook of general Acridology Volume II. University Press, Cambridge

Waldmann B, Zarnack W (1988) Forewing movements and motor activity during roll manoeuvres in flying desert locusts. Biol Cybern 59: 325-335

Waldron I (1967) Neural mechanism by which controlled inputs influence motor output in the flying locust. $47: 213-228$

Waloff Z, Rainey RC (1951) Field studies on factors affecting the displacements of desert locust swarms in eastern Africa. Anti-Locust Bull 9: 1-50 
Weis-Fogh T (1956) The flight of locusts. Sci Am 194: 116

Weis-Fogh T (1964) Biology and physics of locust flight. VIII. Lift and metabolic rate of flying locusts. J Exp Biol 41: 257-271

Weis-Fogh T (1973) Quick estimates of flight fitness in hovering animals, including novel mechanisms for lift production. J Exp Biol 59: 169-230

Whitman DW (1987) Thermoregulation and daily activity patterns in a black desert grasshopper, Taenipoda eques. Anim Behav 35: 1814-1826

Wilson DM, Weis-Fogh T (1962) Patterned activity of co-ordinated motor units, studied in flying locusts. J Exp Biol 39: 643-667

Wolf $\mathrm{H}$ (1990) On the function of a locust flight steering muscle and its inhibitory innervation. J Exp Biol 150: 55-80

Wolf $\mathrm{H}$, Pearson KG (1987) Intracellular recordings from interneurons and motoneruons in intact flying locusts. J Neurosci Methods 21: 345-354

Zarnack W (1988) The effect of forewing depressor activity on wing movement during locust flight. Biol Cybern 59: 55-70 
Zarnack W, Mōhl B (1977) Activity of the direct downstroke flight muscles of Locusta mignatoria (L.) during steering behaviour in flight. I. Patterns of time shift. J Comp Physiol 118: 215-233 